\title{
Stages of Growth of Hamster Retinofugal Axons: Implications for Developing Axonal Pathways with Multiple Targets
}

\author{
Pradeep G. Bhide and Douglas O. Frost \\ Department of Neurology, Massachusetts General Hospital, Boston, Massachusetts 02114 and Neuroscience Program, \\ Harvard Medical School, Boston, Massachusetts 02115
}

Neurons in many regions of the CNS (e.g., cortical areas, thalamic nuclei) are heterogeneous with regard to their afferent and efferent connections. Using the hamster retinofugal system as a model, we investigated the mechanisms by which such connectional heterogeneity arises during ontogeny. Retinal ganglion cell axons were labeled with $1,1^{\prime}$ dioctadecyl-3,3,3',3'-tetramethylindocarbocyanine perchlorate (Dil) in paraformaldehyde-fixed tissue. The fluorescent label was photoconverted to a diaminobenzidine reaction product. The morphology of the axons, including their trajectories, branching patterns, and growth cones, was studied at the level of the dorsal lateral geniculate nucleus (LGd) from embryonic day 14 to adulthood.

In adult hamsters, axons of retinal ganglion cells (RGCs) are spatially segregated at the level of the lateral geniculate nucleus into a superficial optic tract, situated just beneath the pia, and an internal optic tract consisting of fascicles running parallel to the pia within the geniculate. All retinofugal axons project to the midbrain, but only superficial optic tract axons emit collaterals to the LGd. During development, axons in both divisions of the optic tract emit collaterals to the LGd, but by postnatal day 15, collaterals of internal optic tract axons are virtually entirely eliminated, whereas those of superficial optic tract axons have elaborated terminal arbors. Thus, the heterogeneity among different classes of RGCs with respect to their efferent connections emerges by the selective stabilization, by each class, of a unique subset of connections from an initially widespread set shared by all classes.

Thalamic collaterals of RGC axons emerge along established axon trunks, not by bifurcation of the growing tip. This occurs after the axons have grown past the thalamus and, presumably, entered their targets in the midbrain. Growth cones at the tips of elongating axon trunks are larger in size and have a more "complex" morphology compared to the growth cones on collaterals. Axons of RGCs develop in 3

\footnotetext{
Received May 24, 1990; revised Sept. 17, 1990; accepted Sept. 21, 1990.

This work was supported by NIH Grant EY 03465 and March of Dimes Birth Defects Foundation Grants $1-1060$ and 1-1148 to D.O.F. and by a grant from the Charles A. King Trust to P.G.B. Technical support by Wendy West and Margaretha Jacobson and critical comments on earlier versions of the manuscript by Pierre Godement, Sonal Jhaveri, Bob Lieberman, Carol Mason, Christine Métin, Pasko Rakic, Ben Reese, Michael Schwart7, and Fraser Wilson are gratefully acknowledged.

Correspondence should be addressed to Dr. Pradeep G. Bhide, Kennedy Laboratory for Developmental Neurobiology, Department of Neurology, Massachusetts General Hospital East, 149 13th Street, Charlestown, MA 02129.

Copyright (C) 1991 Society for Neuroscience $0270-6474 / 91 / 110485-20 \$ 03.00 / 0$
}

morphologically distinct growth states. First, they elongate to their most distant targets in the midbrain. Then, they simultaneously emit unbranched or poorly branched collaterals to multiple targets. Finally, they elaborate terminal arbors in their definitive targets and eliminate their other collaterals. This developmental strategy may be paradigmatic for the formation of long CNS pathways with multiple targets. Furthermore, these data document, at the singleaxon level, the steps in the elaboration and withdrawal of transient neuronal projections.

Many structures in the CNS consist of multiple classes of neurons, which can be distinguished by a variety of criteria, including somatic and dendritic morphology, neurophysiological properties, and biochemical characteristics (e.g., the expression of a transmitter or a receptor). The different classes of neurons present in a structure receive inputs from or make efferent connections with different subsets of afferents or targets, respectively, among the total number with which the structure is connected (e.g., Wise and Jones, 1977; Keller and Innocenti, 1981; Linden and Perry, 1983; Schneider and Jhaveri, 1983; Innocenti and Clarke, 1984). Conversely, analogous neuronal classes in different nuclei or cortical areas often have similar afferent and efferent connections (Innocenti, 1986; Frost, 1988; Métin and Frost, 1989).

How does the pattern of efferent connections unique to a given neuronal class arise during development? Two broad categories of mechanisms can be envisaged: (1) The connectivity of a particular neuronal class may be established by a developmental program specified by the time the neurons undergo their final mitoses. Support for this possibility comes from experiments in which immature cortical neurons that have just undergone their final mitoses are transplanted to the cortex of hosts of the same or different developmental stage; the transplanted neurons generally form connections appropriate to the class to which they belong (McConnell, 1989). (2) A particular group of neurons may, for some period, follow a common developmental program and initially form identical sets of connections; subsequently, this group of neurons may differentiate into subclasses, each subclass losing some of its original connections and retaining only a characteristic set, thus producing the connectional heterogeneity of the adult structure. Neurons in layer $\mathrm{V}$ of the different neocortical areas appear to establish their projections in this way (O'Leary and Terashima, 1988). Schemes may also be envisaged in which these 2 mechanisms operate sequentially, with a neuron's connectional possibilities becoming limited by the time of its final mitosis and further refined by the elimination of some of its original connections. 
The experiments reported here study the process by which different populations of hamster retinal ganglion cells (RGCs) develop their characteristic sets of connections. In rodents, RGCs are heterogeneous with regard to their efferent connections. For example, in hamsters (Chalupa and Thompson, 1980) and pigmented rats (Linden and Perry, 1983), virtually all RGCs with crossed axons project to the midbrain; $25-50 \%$ of these also project to the dorsal lateral geniculate nucleus of the thalamus (LGd; Martin, 1986). In the hamster, RGCs can be divided into 2 categories based on the trajectories and the sites of termination of their axons. Anterograde degeneration studies (Schneider and Jhaveri, 1983) have shown that RGC axons that have collaterals to the LGd (and that also project to the midbrain) lie just beneath the pial surface, in the superficial optic tract (SOT); RGC axons that project only to the midbrain lie deep in the neuropil of the LGd, in the internal optic tract (IOT), though the SOT may also contain RGC axons that do not have thalamic collaterals.

We labeled individual RGC axons with the carbocyanine dye, 1, 1'-dioctadecyl-3,3,3',3'-tetramethylindocarbocyanine perchlorate (DiI) or with HRP at different pre- and postnatal ages. The morphology, trajectories, and branching patterns of the axons were studied at the level of the LGd.

These observations show that the heterogeneity among RGCs with respect to their cfferent connections emerges in the postnatal period by the differential refinement of an initially homogeneous, more widespread pattern of connections. We also document the stages in the development and the partial elimination of retinothalamic axon collaterals and the morphology of growth cones at each stage. Further, we show that RGC axons develop in 3 morphologically defined "growth states," a developmental strategy that, we hypothesize, may be common to the formation of many "long" axonal pathways with multiple targets.

\section{Materials and Methods}

Animals

Syrian golden hamsters (Mesocricetus auratus) were used. The first 24 hr following mating are designated as embryonic day 0 (E0), and the first $24 \mathrm{hr}$ following birth as postnatal day 0 (P0). The gestation period is $15.5 \mathrm{~d}$. Perfusions were conducted under anesthesia induced by hypothermia (P0-P3), ether (P4-P15), or sodium pentobarbital (E14 and $>$ P15). Hamsters aged E14 to adulthood (older than P60) were used. Table 1 lists the numbers of hamsters in each age group.

\section{In vitro DiI labeling experiments}

DiI (Molecular Probes, OR) was used as an anterograde label in fixed tissue (Godement et al., 1987). The labeling technique was slightly modified from that described by these authors.

Preparation of Dil-coated glass. Fine glass tubing with an outer diameter of approximately $10 \mu \mathrm{m}$ was pulled by flaming glass capillaries on a Bunsen burner. The tubing was cut into lengths of approximately $2 \mathrm{~mm}$. A solution of DiI in absolute ethanol was poured over the pieces, and the ethanol was allowed to evaporate, leaving a uniform coating of crystalline DiI on the glass. The glass pieces were used immediately or stored with a desiccant at $4^{\circ} \mathrm{C}$ for later use.

Optic disk labeling. Anesthetized hamsters were perfused with $4 \%$ paraformaldehydc in $0.1 \mathrm{M}$ phosphate buffer $(\mathrm{pH}, 7.2)$, and the calvarium was removed to expose the brain. The cornea, ciliary ring, and lens were removed from the right eye to expose the optic disk. One, or occasionally 2, DiI-coated glass pieces were inserted into the optic disk. The head, with the glass pieces embedded within the eye, was kept in fixative at room temperature for 1-6 months, after which time the brain was removed. In some cases, glass pieces were inserted in both eyes.

Optic nerve labeling. Hamsters were perfused with $4 \%$ paraformaldehyde in $0.1 \mathrm{M}$ phosphate buffer $(\mathrm{pH}, 7.2)$, and their brains were removed and stored in fixative at $4^{\circ} \mathrm{C}$ for $24-48 \mathrm{hr}$. A glass piece coated with DiI was inserted into the optic nerve just rostral to the optic chiasm. The brain, with the glass piece in place, was kept in fixative at room temperature for 1-6 months. Deposition of Dil in the optic nerve, rather than in the disk, reduced the diffusion time by $2-3$ weeks. However, in hamsters younger than $\mathrm{P} 9$, deposition of $\mathrm{DiI}$ in the optic nerve was less successful because the optic nerve was much thinner and more delicate than that in older hamsters.

Processing DiI-labeled material. Brains were sectioned on a vibratome in the coronal plane at a thickness of $100 \mu \mathrm{m}$, and sections were collected in $0.1 \mathrm{M}$ phosphate buffer $(\mathrm{pH}, 7.2)$ and stored at $4^{\circ} \mathrm{C}$. In most cases, the fluorescent DiI label was photoconverted to a stable diaminobenzidine (DAB; Sigma) reaction product using the method of Sandell and Masland (1988). Briefly, each section was immersed in approximately $2 \mathrm{ml} 0.15 \%$ DAB solution in $0.1 \mathrm{M}$ Tris buffer $(\mathrm{pH}, 8.2)$ in a "culture microslide" (VWR Scientific) and viewed under a fluorescence microscope equipped with a 100-W mercury lamp and a $10 \times$ (numerical aperture [NA], 0.3) or $20 \times(\mathrm{NA}, 0.4)$ Olympus long-working-distance objective. Once the area of interest was located in the field of view, the section was left in that position for the duration of the oxidation procedure. The DAB solution was changed after the first $10 \mathrm{~min}$ and, if a brownish discoloration (background) of the section was present, again after another $20 \mathrm{~min}$. Following every change, the section was repositioned to bring into view the area originally selected for oxidation. The rate of photoconversion depended on the brightness of the label, type (NA and power) of objectives lens, and the brightness of the light source. A bright DiI-label, $10 \times$ objective lens with an NA of 0.3 and a new $100-W$ lamp produced the fastest rate of photoconversion. In our experiments, the photoconversion was complete within 30-60 min. The photoconverted sections were osmicated ( $1 \%$ aqueous osmium tetroxide, $4^{\circ} \mathrm{C}, 45 \mathrm{~min}$ ) and flat embedded in Epon. Dil-labeled axons containing the photoconverted DAB appeared dark brown and were photographed and/or reconstructed from serial sections using a drawing tube.

Additional sections were mounted on slides using $90 \%$ glycerol and $5 \% n$-propyl gallate (Sigma) in $0.1 \mathrm{M}$ phosphate buffer to retard fading of the fluorescence and examined in a fluorescence microscope. Some fading of the label occurred during storage irrespective of whether the sections were mounted with the medium described above or stored in phosphate buffer. The fluorescent-labeled axons were photographed but not reconstructed using a drawing tube because the label tended to fade during the relatively long time required to prepare the drawing. Because $n$-propyl gallate blocks the formation of free radicals, a mechanism that retards the fading of fluorescent label, it also interferes with photoconversion because free radicals are essential for the oxidation of DAB. Therefore, sections mounted with $n$-propyl gallate could not be photooxidized.

In hamsters older than $24 \mathrm{~d}$ of age, though Dil-labeled fascicles of axons could be seen in the optic tract and the LGd, it was difficult to resolve individual axons. The reasons for this difficulty are unclear. However, when the dye was used in vivo (P. G. Bhide and D. O. Frost, unpublished observations), individual labeled axons and their arbors could be resolved in hamsters of all ages. In our experiments, RGC axons and arbors in hamsters older than $24 \mathrm{~d}$ of age were labeled using the in vitro HRP technique (see below).

\section{In vitro $H R P$ labeling experiments}

The procedure is a modification of that described by Mason (1985) and Sretavan and Shatz (1986) and described in detail by Langdon and Frost (1990). Anesthetized hamsters were perfused with cold, oxygenated Ringer's solution for 2-4 min. The brain was removed and placed in cold, oxygenated Ringer's solution; the cerebral cortex was cut away to expose the diencephalon, and the brain was sliced in the midsagittal plane. After removing the dura, a pellet of HRP (Sigma, type VI) about $50 \mu \mathrm{m}$ (P0-P9) or $100 \mu \mathrm{m}$ (P12-adult) in diameter and dried onto the tip of a micropipette was deposited in the optic tract (OT) of each hemisphere at the border between the LGd and the ventral lateral geniculate nucleus (LGv). The slices were then incubated in oxygenated Ringer's solution at $27^{\circ} \mathrm{C}$ for $2-3 \mathrm{hr}(\mathrm{PO}-\mathrm{P9})$ or at $15^{\circ} \mathrm{C}$ for $3-4 \mathrm{hr}(\mathrm{P} 12-$ adult); they were then fixed by immersion in $1 \%$ paraformaldehyde and $1.25 \%$ glutaraldehyde in $0.1 \mathrm{~m}$ cacodylate buffer $(\mathrm{pH}, 7.2)$ for approximately $2 \mathrm{hr}$ at $4^{\circ} \mathrm{C}$ and stored in $0.1 \mathrm{M}$ cacodylate buffer at $4^{\circ} \mathrm{C}$ overnight. Then, they were sectioned on a vibratome in the coronal plane at a thickness of $100 \mu \mathrm{m}$ and processed for HRP histochemistry using DAB, cobalt chloride, and nickel ammonium sulfate (Adams, 1981). The sections were osmicated as described above and embedded flat in Epon. 
Table 1. The numbers of hamsters used, RGC axon collaterals fully reconstructed from serial sections, and growth cones analyzed for each age group

\begin{tabular}{|c|c|c|c|c|c|c|c|c|}
\hline \multirow[b]{2}{*}{ Age } & \multicolumn{2}{|c|}{ Hamsters } & \multicolumn{2}{|c|}{ Collaterals } & \multicolumn{2}{|c|}{ Complex growth cones } & \multicolumn{2}{|c|}{$\begin{array}{l}\text { Simple growth cones } \\
\text { and growing tips }\end{array}$} \\
\hline & HRP & DiI & $\overline{\text { SOT }}$ & IOT & SOT & IOT & SOT & IOT \\
\hline E14 & - & 6 & - & - & 12 & 1 & - & - \\
\hline P0 & 6 & 5 & 10 & 17 & 6 & - & 10 & 28 \\
\hline P1 & 2 & 4 & 4 & 6 & 1 & - & 4 & 6 \\
\hline $\mathbf{P} 2$ & 5 & 3 & 9 & 12 & - & - & 9 & 18 \\
\hline P3 & 3 & - & 2 & 2 & - & - & 2 & 2 \\
\hline P4 & 4 & 6 & 6 & 10 & - & - & 2 & 3 \\
\hline P6 & 2 & 3 & 4 & - & - & - & 1 & - \\
\hline P9 & - & 3 & 7 & 7 & - & - & 2 & - \\
\hline P12 & 3 & - & 4 & 5 & - & - & - & - \\
\hline P15 & 3 & 7 & 5 & 2 & - & - & - & - \\
\hline P24 & 4 & - & 3 & - & - & - & - & - \\
\hline P30 & 3 & - & 2 & - & - & - & - & - \\
\hline$>$ P60 (adult) & 4 & - & 2 & - & - & - & - & - \\
\hline
\end{tabular}

Labeled processes extended $2-4 \mathrm{~mm}$ from the site of HRP deposition, depending on the size of the pellet. Although, at the site of deposition of the HRP, individual fibers could not be resolved because of the presence of a large number of labeled profiles, they were clearly visible away from the site and were photographed or reconstructed from serial sections using a drawing tube.

\section{Results}

\section{Technical comments}

Both the in vitro DiI and the HRP techniques produced good labeling of axons at every age studied. However, the in vitro HRP technique was less effective than the DiI technique in labeling filopodia, lamellopodia, and processes of finer caliber. Therefore, virtually all the data presented here are from the DiIlabeled material. Data from HRP-labeled material are identified where appropriate. Preliminary electron microscopic analysis of both the HRP and the photooxidized DiI material shows good labeling and structural preservation (P. G. Bhide and D. O. Frost, unpublished observations).

The data presented below were analyzed qualitatively. It was not possible to obtain meaningful quantitative measurements of developmental changes in parameters such as the distribution of different types of growth cones, the number of collaterals per axon, collateral length, and the cross-sectional areas of axonal arbors. This is because axons were chosen for reconstruction by a nonrandom procedure: Well-labeled growth cones, collaterals, or terminal arbors were identified in regions where the density of labeled processes was sufficiently low to permit unequivocal tracing of these elements to more proximal parts of the same axons from serial sections. Conceivably, this sampling procedure could have introduced quantitative biases in our data. However, our data suggest that our sample of axons contains all the qualitatively distinguishable types of each axonal element.

\section{Definition of terms}

Elongating $R G C$ axon: An RGC axon that is growing towards its midbrain targets and that has not yet emitted a collateral (but may emit filopodialike extensions).

Collateral: An axonal process, approximately $5 \mu \mathrm{m}$ long or longer, emerging from an RGC axon trunk. A collateral generally terminates in a growth cone, growing tip, or arbor. Collaterals that do not have terminal specializations are referred to as regressing collaterals; many of these are less than $5 \mu \mathrm{m}$ long.

Filopodium or flopodiumlike process: Axonal processes of very fine caliber that emerge from a growth cone (see Fig. 2a,e, arrowheads) or a developing axon trunk, respectively (see Fig. $2 a, d, h-j$, arrows). It is generally of uniform thickness, but sometimes may terminate in a swelling (see Figs. $1 a-d, 2$ ).

Growth cone: A prominent enlargement at the tip of an axon trunk or a collateral that may be "complex" or "simple" (see below).

Growing tip: A spherical or slightly elongated terminal expansion, less than $3 \mu \mathrm{m}$ in size, located on unbranched axon collaterals (see Figs. $3 e, f ; 4 a, b, d, e, n ; 8 a-c, i)$. It is smaller than a "simple" growth cone (which is about $5 \mu \mathrm{m}$ in size) and resembles the varicosities present on developing terminal arbors (cf. Fig. $4 n, q$, arrow).

Varicosity: A swelling at the site of emergence of a collateral from an axon trunk (e.g., Fig. $1 e, g, h$ ), along an axon trunk, along a collateral (see Fig. $1 h$ ), or along or at the tip of a terminal arbor (see Fig. 4q, arrows). The difference, at the light microscopic level, between a growing tip and a varicosity is its location. Growing tips, as the name indicates, are at the tips of developing collaterals.

Terminal arbor: An axonal "tree" formed when an axon collateral undergoes repeated branching. If a collateral undergoes only 2-4 divisions, the resulting arbor is referred to as "primitive" (see Figs. $4 k-m, 8 j-l, o$ ). A "developing" arbor is more highly branched than a "primitive" arbor but cannot yet be classified into one of the 3 types described by Erzurumlu et al. (1988) in the adult.

\section{Growth cones}

Based on their size, growth cones were classified into 2 types: (1) "Complex" growth cones have 10-50- $\mu$ m-long terminal expansions (Figs. $1 a-d, 2 a-j$ ). Filopodial extensions up to $15 \mu \mathrm{m}$ in length emerge from the terminal expansions or from preterminal regions (Figs. $1 a-d, 2 a-j$ ). Some complex growth cones may have well-defined lamellopodia (Fig. 2e). This type of growth cone was common on E14, rare by $\mathrm{Pl}$, and absent thereafter. 

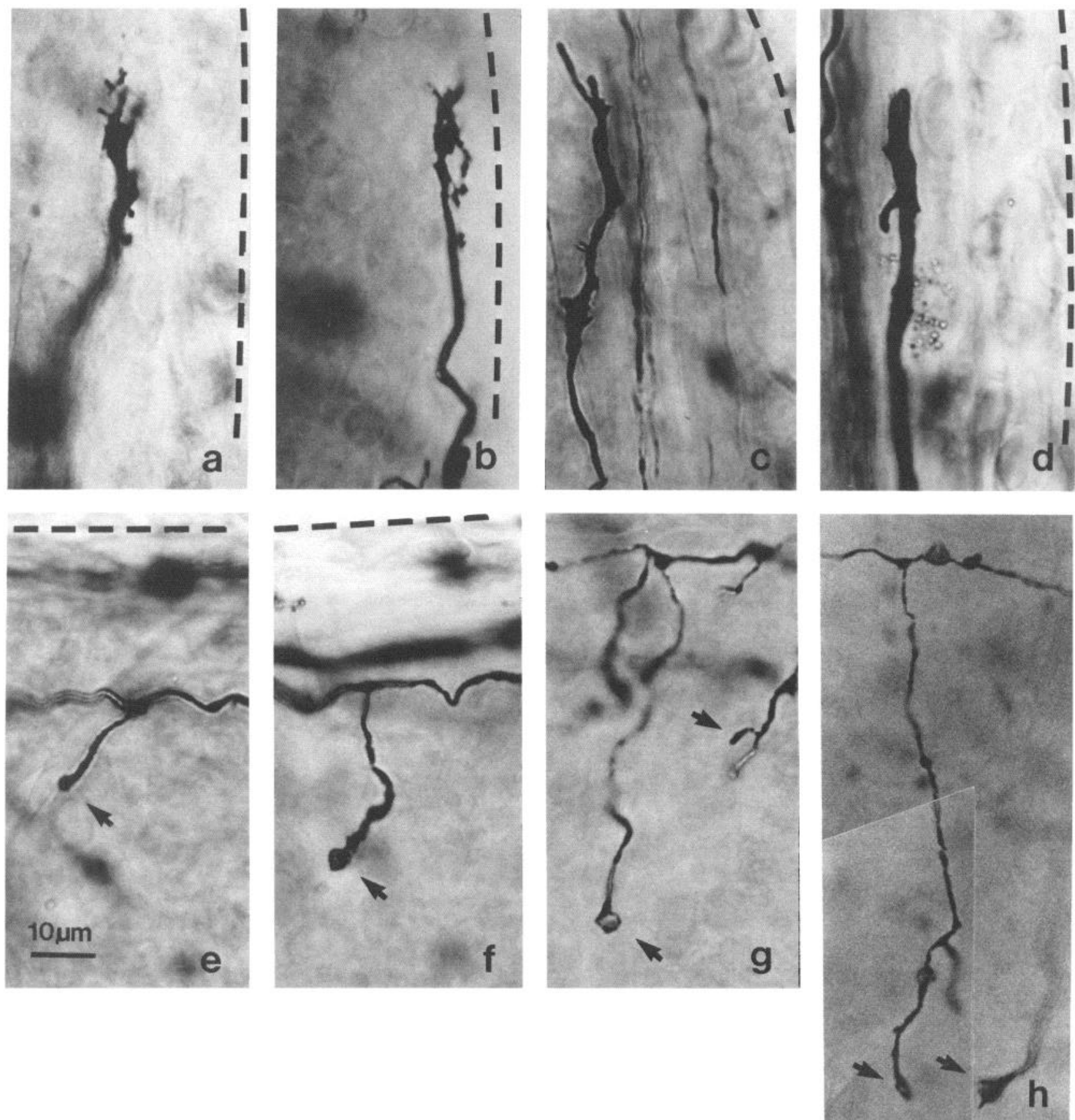

Figure 1. Growth cones on RGC axons at level of LGd on E14 and P0. Dil-coated glass was placed in the contralateral optic disk in paraformaldehyde-fixed tissue. The fluorescent label was photoconverted to a stable DAB reaction product. $a-d$ show complex growth cones on elongating SOT axons; $a$ and $b$ are from E14, and $c$ and $d$ from P0 hamsters. $e-h$ show simple growth cones (arrows) from P0 hamsters; $e$ and $f$ are on SOT collaterals, and $g$ and $h$ are on IOT collaterals. The broken lines indicate the pial surface.

On P0, complex growth cones lacked lamellopodia, had fewer filopodia, and were smaller in size, compared to those on E14 (cf. Fig. $2 a-g, h-j$ ). These differences were not quantified. (2) "Simple" growth cones have terminal expansions approximately $5 \mu \mathrm{m}$ in cross-sectional diameter (Figs. $1 e-h, 3 a-d, g, h$ ). The terminal expansion may be cuneiform (e.g., Fig. $8 a$ ), clubshaped (e.g., Fig. $8 g$ ), or elongated (e.g., Fig. 8 h). Filopodia are absent, but lamellopodia are often present (Fig. $3 b, c$, arrowheads). The difference, at the light microscopic level, between simple growth cones and growing tips is that the former have larger cross-sectional diameters.

There is a very gradual, irregular change in the cross-sectional diameter of an axon trunk in the vicinity of a complex growth cone (Figs. $1 a-d, 2$ ). As a result, most of the complex growth cones do not have a distinct "shank" region that separates the terminal expansion from the axon trunk. Therefore, it was not possible, without electron microscopic analysis, to reliably delineate complex growth cones to measure their dimensions and 

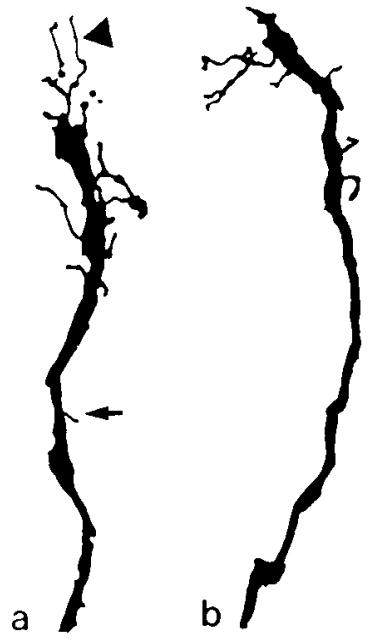

C

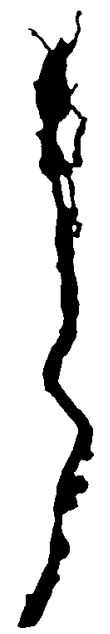

E14

$10 \mu \mathrm{m}$

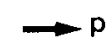

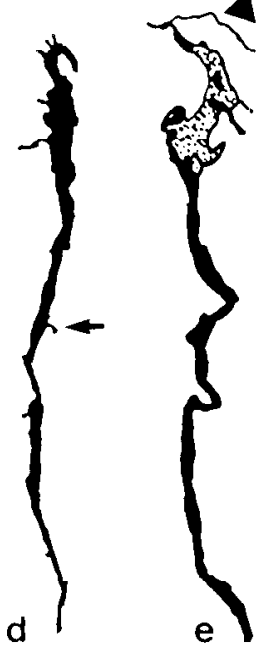

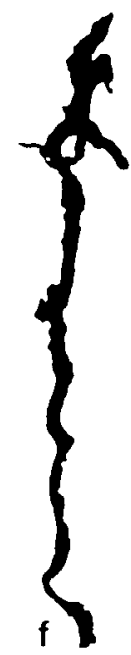

9

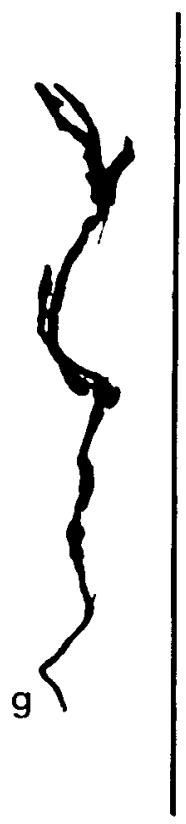

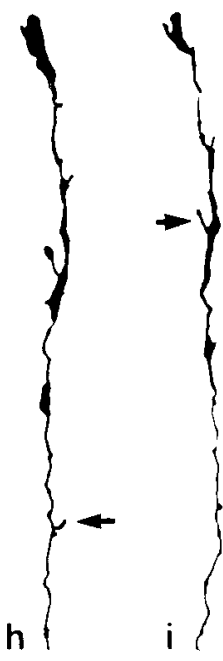

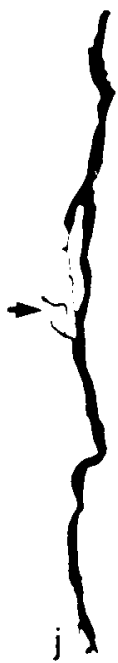

PO

Figure 2. Camera lucida drawings of DiI-labeled, photoconverted complex growth cones on elongating RGC axons at level of LGd on E I4 and PO. All growth cones were situated in the SOT, except that shown in $f$, which was approximately $150 \mu \mathrm{m}$ deep to the pial surface, in the IOT. The size of the growth cones appears to decrease from E14 to P0. Arrows in $a, d, h, i$, and $j$ point to filopodialike extensions commonly seen on elongating axons. Arrowheads in $a$ and $e$ indicate filopodia on growth cones. The growth cone in $e$ has a prominent lamellopodium. $p$ indicates the direction of the pial surface.

to compare with those of simple growth cones or growing tips.

Complex growth cones are situated virtually exclusively on growing axon trunks in the SOT, which lies just beneath the pia. [The single exception to this in our sample (Fig. $2 f$ ) was approximately $150 \mu \mathrm{m}$ beneath the pial surface, in the IOT.] This is consistent with previous studies indicating that growing RGC axons elongate almost exclusively on the surface of the diencephalon, in close proximity to the pia or to subpial glial

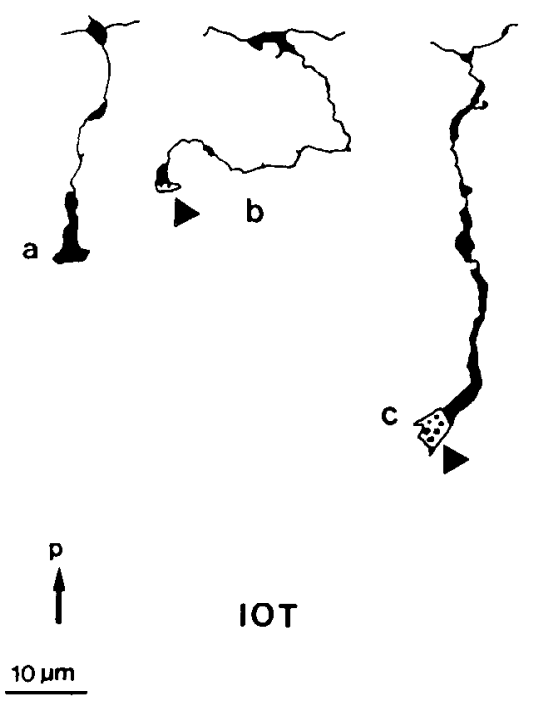

PO

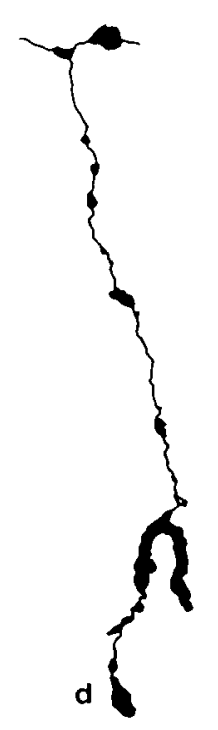

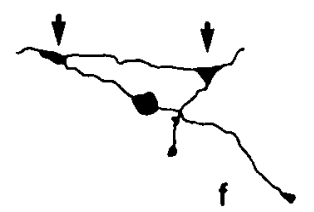

PO

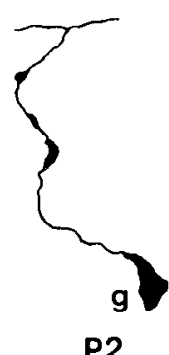

SOT

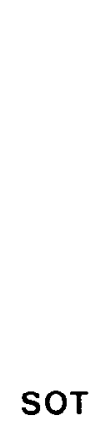

P2

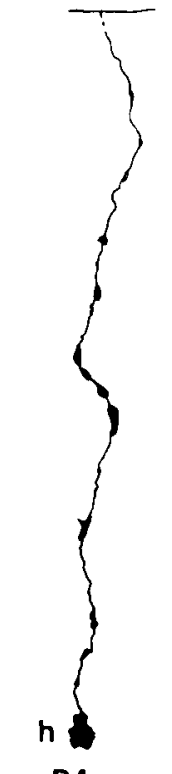

P4

Figure 3. Camera lucida drawings of DiI-labeled, photoconverted retinal axon collaterals on $P 0, P 2$, and $P 4$. Collaterals $a-c, g$, and $h$ terminate in simple growth cones. The growth cones do not have filopodia, but lamellopodia are often present $(b, c, a r r o w h e a d s)$. Collateral $d$ terminates either in a single, large, bifurcated growth cone or in 2 separate, simple growth cones; the distinction is difficult to make at the light microscopic level. Collaterals $e$ and $f$ terminate in growing tips. The arrows in $f$ indicate 2 collaterals emerging from the same SOT axon trunk, an example of multiple collateral emission that is common in early development. $p$ indicates the direction of the pial surface. 

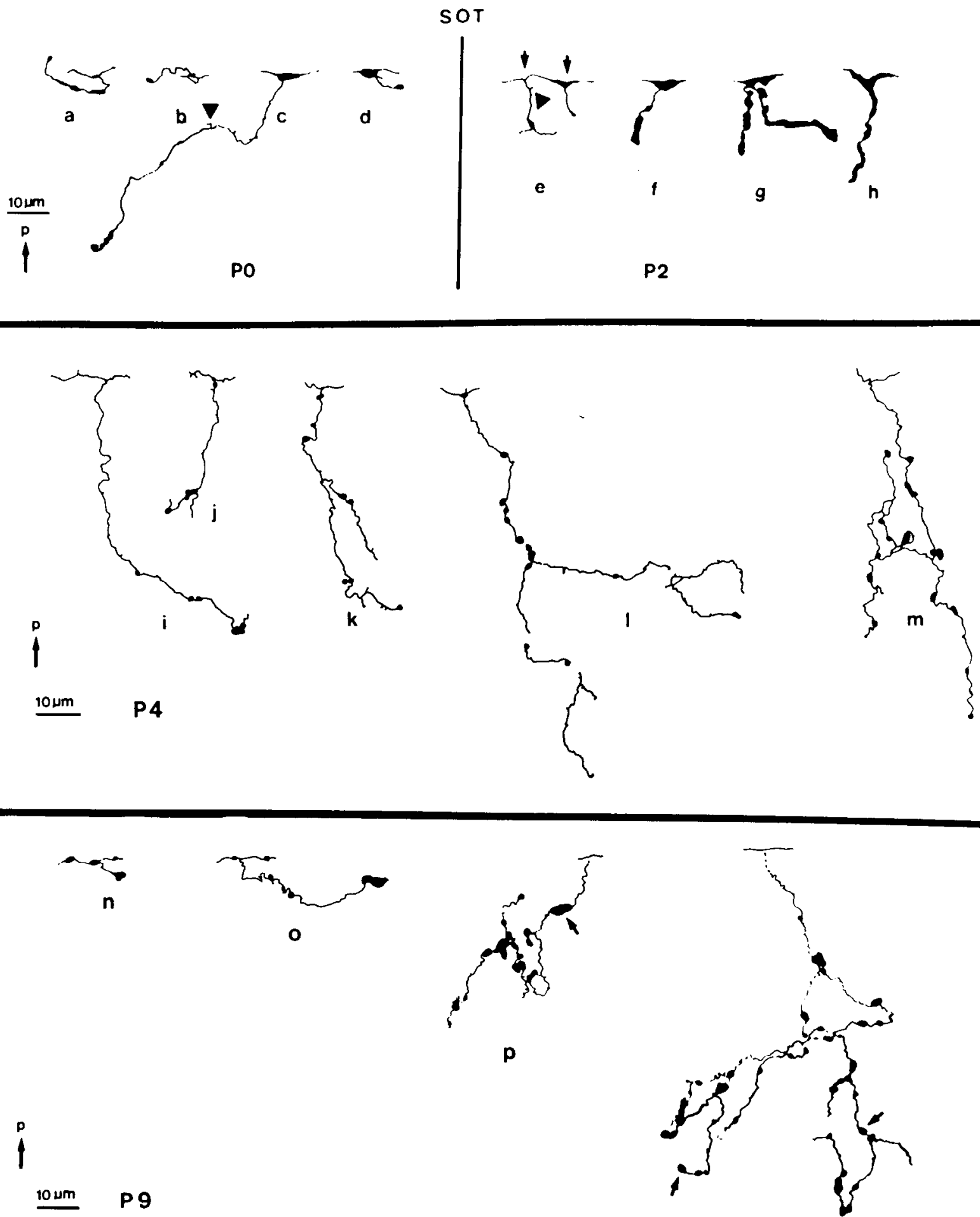

o

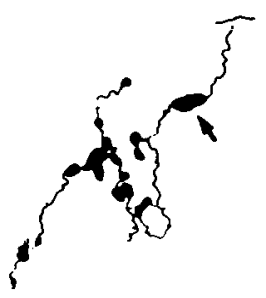

$\mathbf{p}$

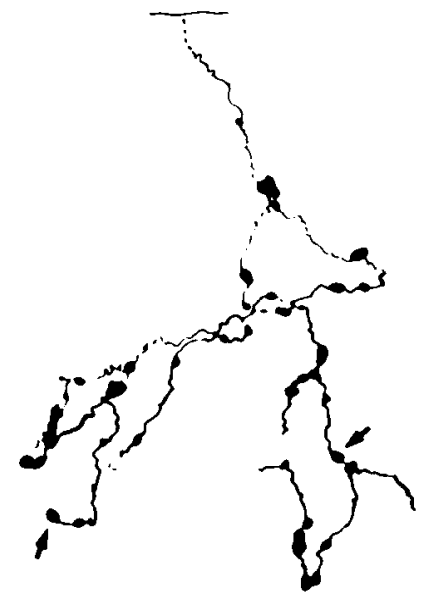

q

Figure 4. Camera lucida drawings of DiI-labeled, photoconverted SOT axon collaterals on $P 0, P 2, P 4$, and $P 9$. Collaterals $c$, $f, g$, and $o$ terminate in simple growth cones, whereas collaterals $a, b, d, e, h$, and $n$ terminate in growing tips. Collateral $i$ terminates in a swelling that is neither a typical growth cone nor a growing tip. Collaterals $j$ and $k$ terminate in primitive arbors, and collaterals $l, m, p$, and $g$ terminate in developing arbors. The arrows in $p$ and $q$ indicate axonal varicosities (see definition of terms in Results). The arrows in $e$ mark 2 collaterals emerging from the same axon trunk. The arrowheads in $c$ and $e$ indicate transient, short side branches. The breaks in the drawing of collateral $l$ represent discontinuous labeling, encountered occasionally at this and later ages. The cause of these breaks is unknown. The apparently "broken" ends of the axon across a discontinuity were found within a single section and were sufficiently far from other labeled profiles to assure that they were parts of the same axon. $p$ indicates the direction of the pial surface. 

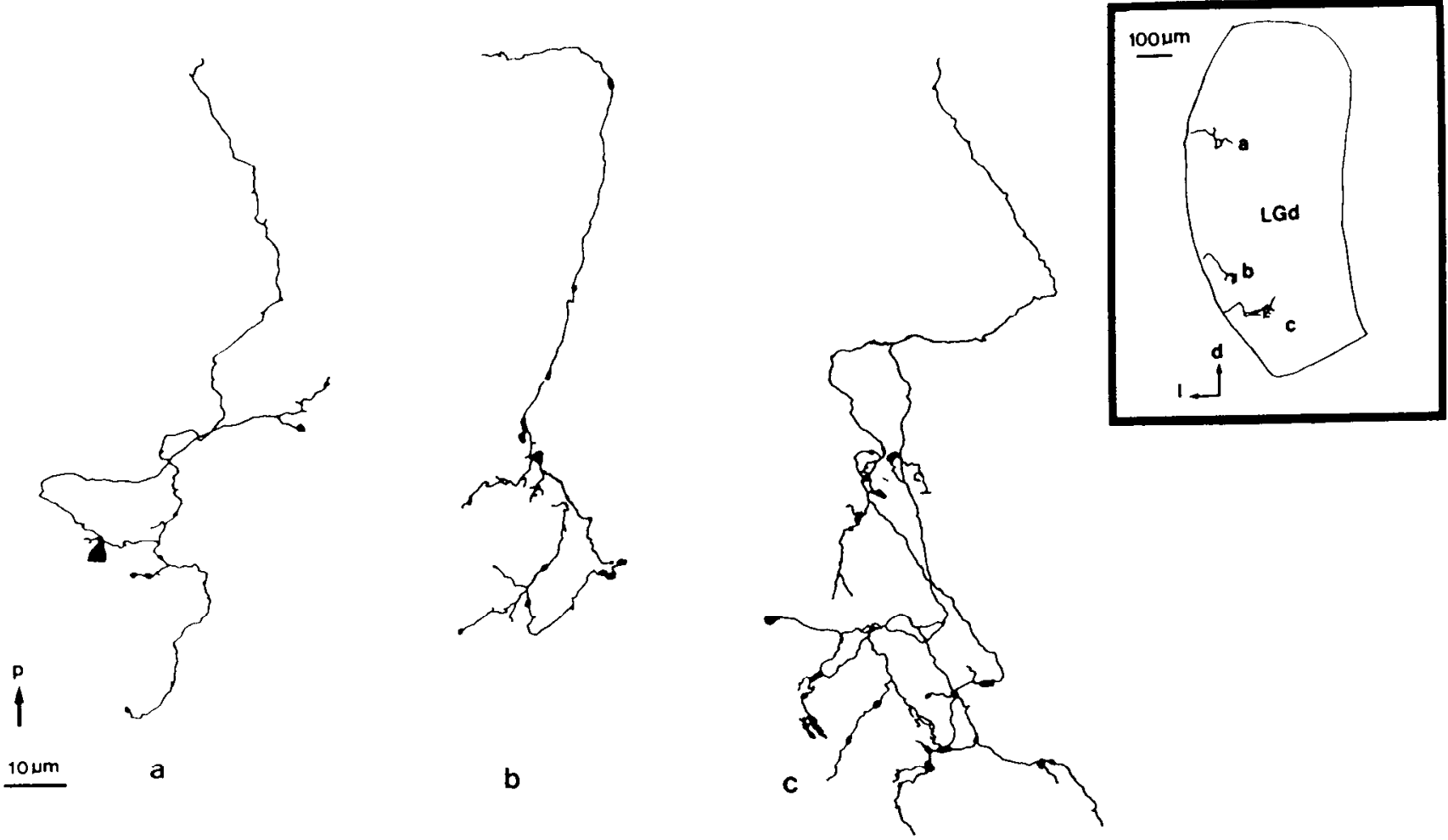

P15
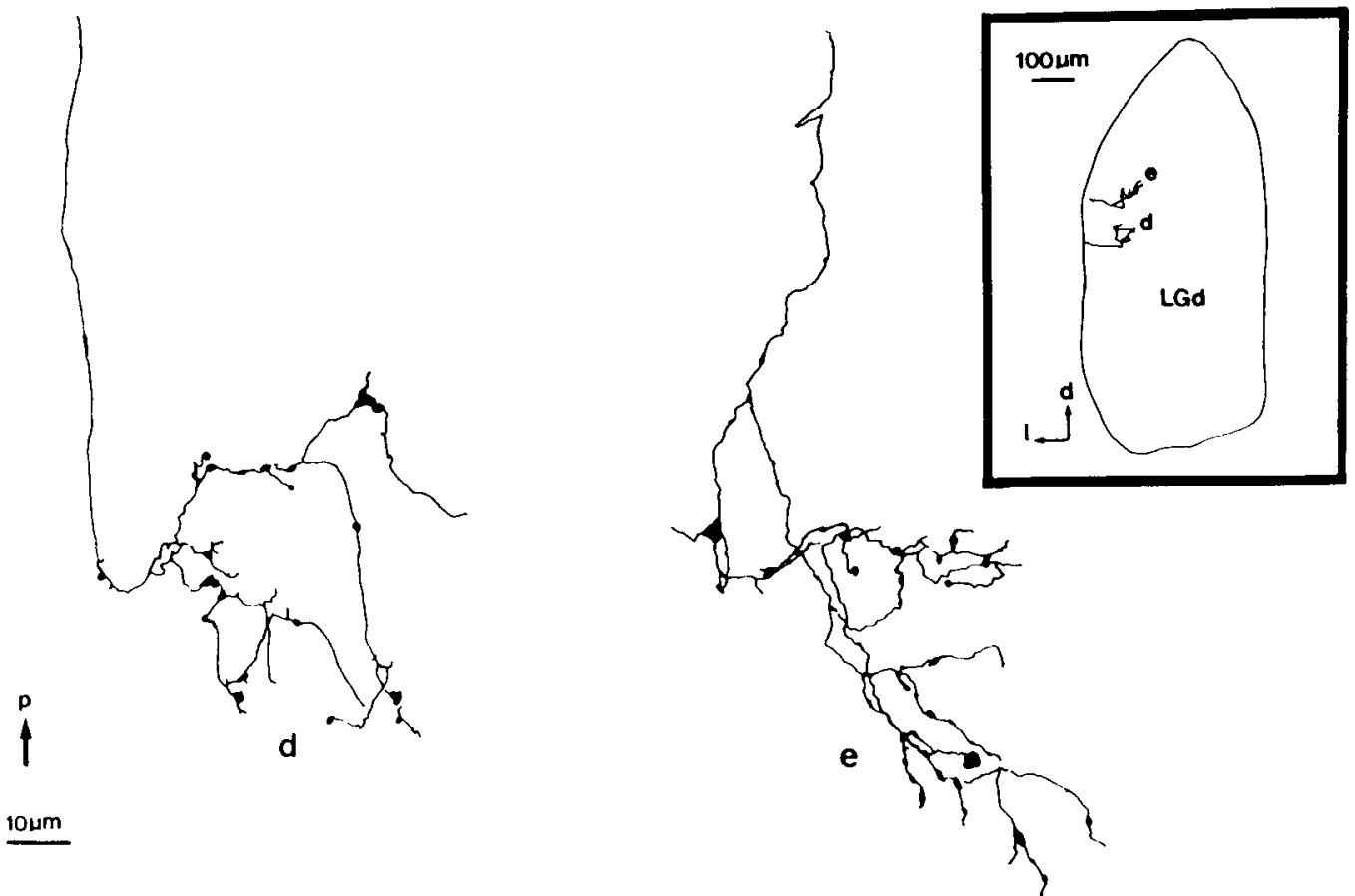

Figure 5. Camera lucida drawings of SOT axon collaterals bearing developing terminal arbors on $P 12$ and $P 15$. Collateral $d$ is from HRP-labeled material; others are from DiI-labeled, photoconverted material. Collaterals bearing growth cones are absent at this and later ages. The insets indicate the location of the collaterals within the LGd. $p$ indicates the direction of the pial surface, $d$ is dorsal, and $l$ is lateral. 


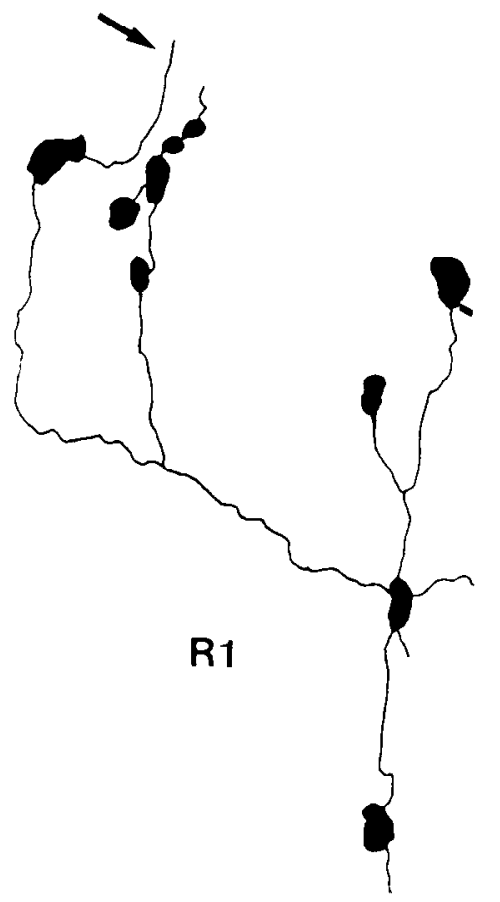

$10 \mathrm{um}$

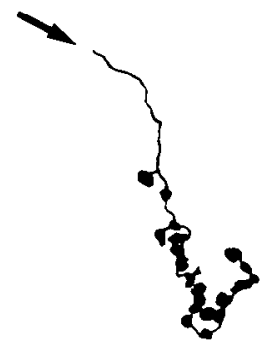

R2 .

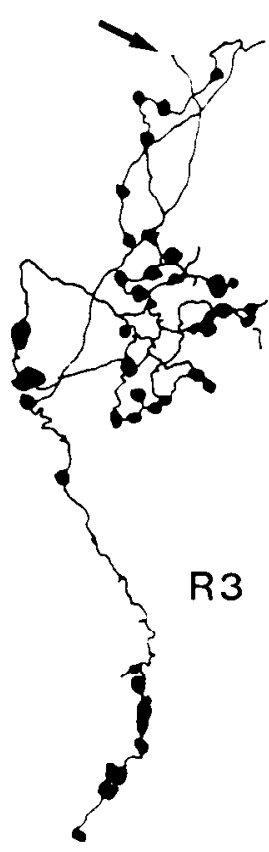

\section{P15}

Figure 6. Camera lucida drawings of 3 types of HRP-labeled, retinal axon arbors in LGd on P15. This is the earliest age in our study when the 3 types of arbors could be distinguished. The arrows indicate presumptive preterminal axons.

elements (Walsh et al., 1985; Bovolenta and Mason, 1987; Guillery and Walsh, 1987). Simple growth cones are located on developing collaterals of both SOT and IOT axons.

\section{Development of retinal axons}

The development of SOT axons and that of IOT axons are described separately below. The term "SOT" refers to those axons remaining between the pial surface and the gray matter of the diencephalon throughout their course over the lateral geniculate nucleus. The term "IOT" denotes those axons leaving the main OT at the level of the LGv and passing in fascicles through the LGv and LGd towards the midbrain.

\section{SOT axons and collaterals}

E14. At this age, axons running just beneath the pial surface have complex growth cones (Figs. $1 a, b ; 2 a-g$ ). They grow to their targets in the midbrain without emitting collaterals to the LGd, though short, filopodialike extensions may emerge from them (Fig. 2a,d, arrows).

$P 0$ and $P 2$. Most SOT axons are branchless and run in fascicles under the pial surface. Some emit short, filopodialike extensions (Fig. $2 h-j$, arrows). On P0 but not P2, some axons are still tipped with complex growth cones (Figs. $1 c, d ; 2 h-j$ ). On P0 and P2, short (approximately $25-\mu \mathrm{m}$ long), fingerlike collaterals with growing tips (Figs. $3 e, f ; 4 a, b, d, e, h$ ) or with simple growth cones (Figs. $3 g, 4 c, f, g$ ) emerge from some SOT axons. On P2, some collaterals may be longer than $25 \mu \mathrm{m}$ (Fig. $3 g$ ); occasionally even on P0, a collateral may be up to $90 \mu \mathrm{m}$ in length (e.g., Fig. $4 c$ ). On $\mathrm{P} 0$ and $\mathrm{P} 2$, generally, the collaterals are restricted to the outer half of the LGd. Multiple collaterals may emerge from a single axon (Figs. $3 f$, $4 e$; see Fig. $10 a$, arrows). The collaterals often have short ( $<5 \mu \mathrm{m}$ long) side branches of uniform diameter (Fig. 4c,e, arrowheads). These side branches may correspond to the side branches found on the developing retinogeniculate axons of kittens (Sretavan and Shatz, 1986).

P4. Complex growth cones of the kind seen on E14 and P0 at the tips of elongating RGC axon trunks are absent, suggesting that all RGC axon trunks have grown past the LGd towards their midbrain targets. Collaterals terminate in growing tips (not illustrated), in simple growth cones (Fig. $3 h$ ), in primitive arbors (Fig. $4 k, l$ ), or in developing arbors (Fig. $4 \mathrm{~m}$ ). The largest of the primitive arbors spans a cross-sectional area approximately 30 $\mu \mathrm{m}$ in diameter. Side branches such as those seen on P0 (Fig. $4 c, e$, arrowheads) are rare.

P9. Although collaterals with the same range of lengths, terminal specializations, and branching characteristics as was seen on $\mathrm{P} 4$ are present, those with growing tips or simple growth cones (Fig. $4 n, o$, respectively) are less common than those with primitive (not illustrated) or developing (Fig. $4 p, q$ ) terminal arbors. Terminal arbors of varying complexity are seen; many span a cross-sectional area of up to $120 \mu \mathrm{m}$ in diameter. There are varicosities about $2 \mu \mathrm{m}$ in diameter, along and at the tips of branches that constitute the terminal arbors (Fig. $4 p, q$, arrows).

P12. SOT collaterals with developing arbors of varying complexity are seen (Fig. $5 a-c$ ). Some terminal arbors are more complex than those seen on P9. Varicosities on the terminal branches constituting the arbors, similar to those seen on P9 

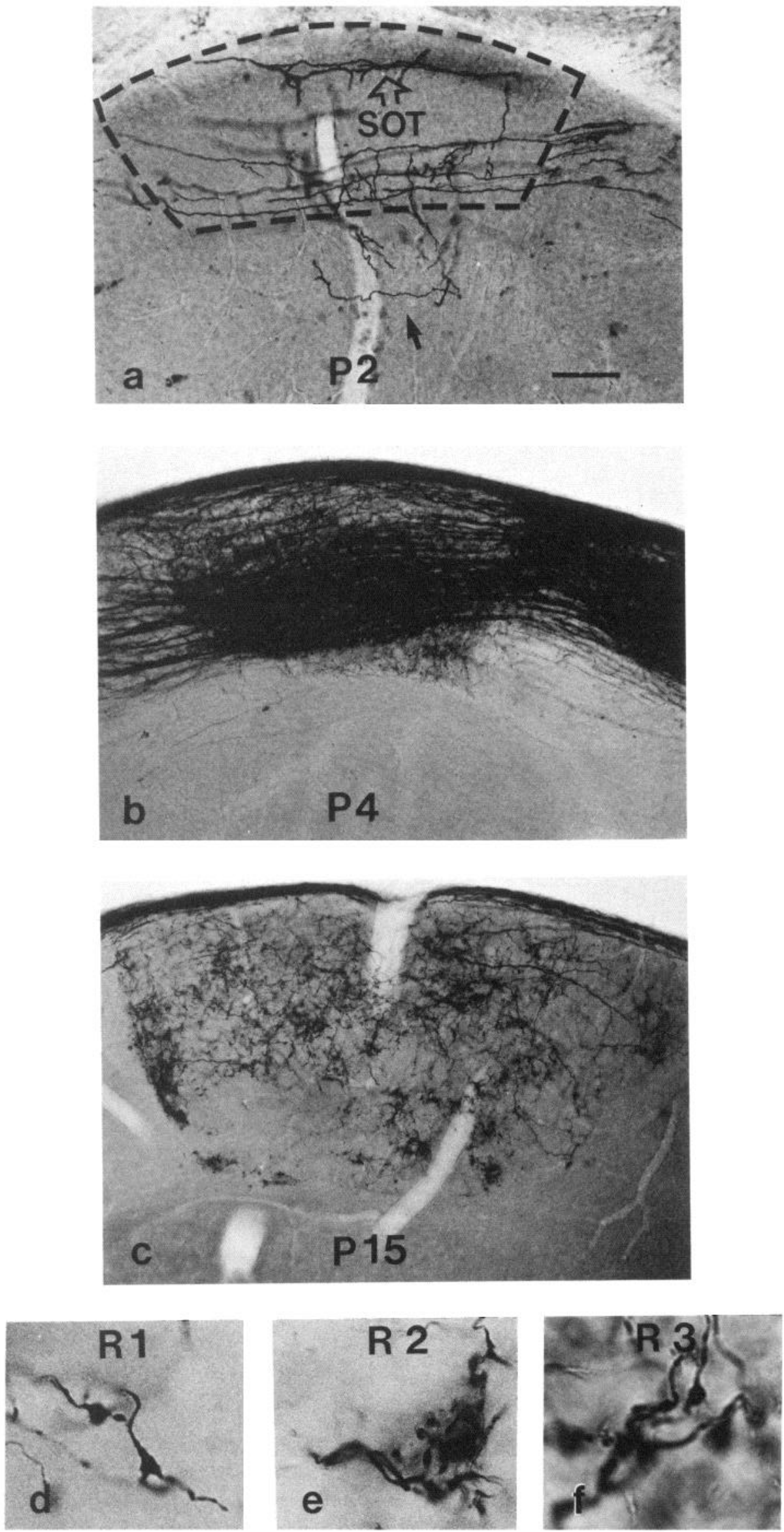

Figure 7. DiI-labeled, photoconverted RGC axons and terminals in thalamus on P2, P4, and P15. The LGd is outlined by broken lines in $a$. The relatively greater development of IOT collaterals compared to SOT collaterals is apparent in $a$. The solid arrow in $a$ indicates an IOT collateral that has entered the thalamic somatosensory (VB) nucleus. The robust labeling in $b$ was obtained by placing DiI-coated glass in the optic nerve just rostral to the optic chiasm on P4. The high density of labeling (compare with $a$, in which DiI was placed in the optic disk) is not appropriate for tracing single axons. Maturing terminal arbors can be seen in $c$. Most IOT axon trunks are not in the plane of focus. $d-f$ show the 3 types of RGC axon terminals from a P15 hamster, which are similar to those described in the adult by Erzurumlu et al. (1988). Scale bar, $100 \mu \mathrm{m}$ for $a-c, 10$ $\mu \mathrm{m}$ for $d-f$. The pial surface is at the top in $a, b$, and $c$. 

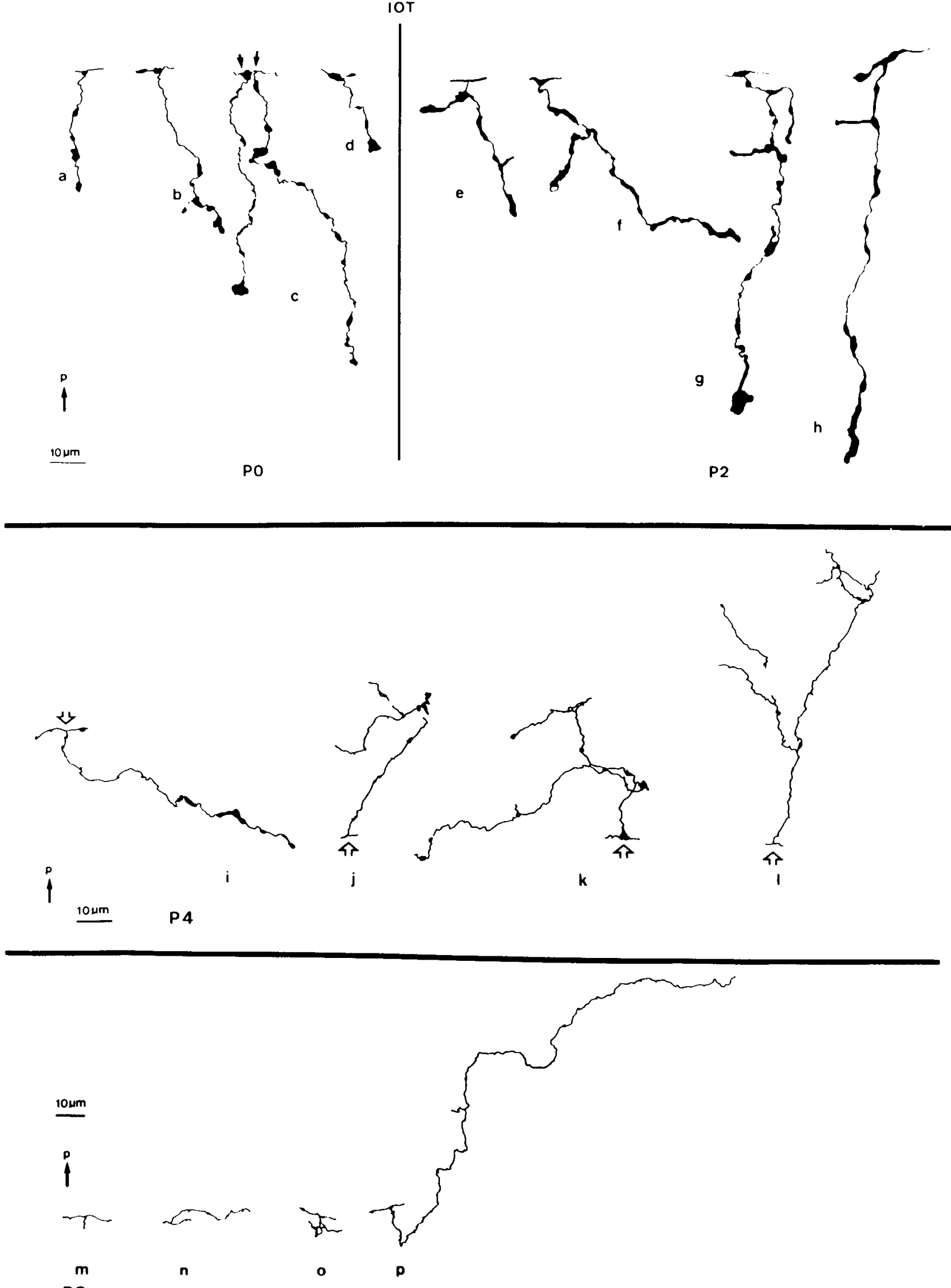

P9

Figure 8. Camera lucida drawings of DiI-labeled, photoconverted IOT axon collaterals on $P 0, P 2, P 4$, and $P 9$. Collaterals $a-h$ end in growth cones, collateral $i$ ends in a growing tip, and collaterals $j-l$ have primitive terminal arbors. The arrows in $c$ indicate 2 collaterals arising from the 


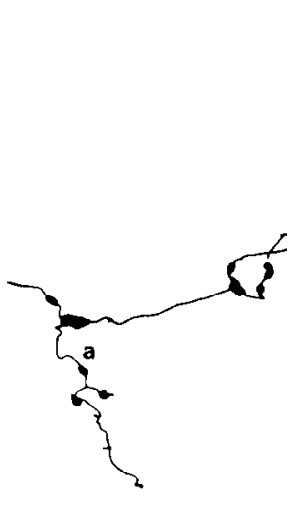

p

toum

$10 T$
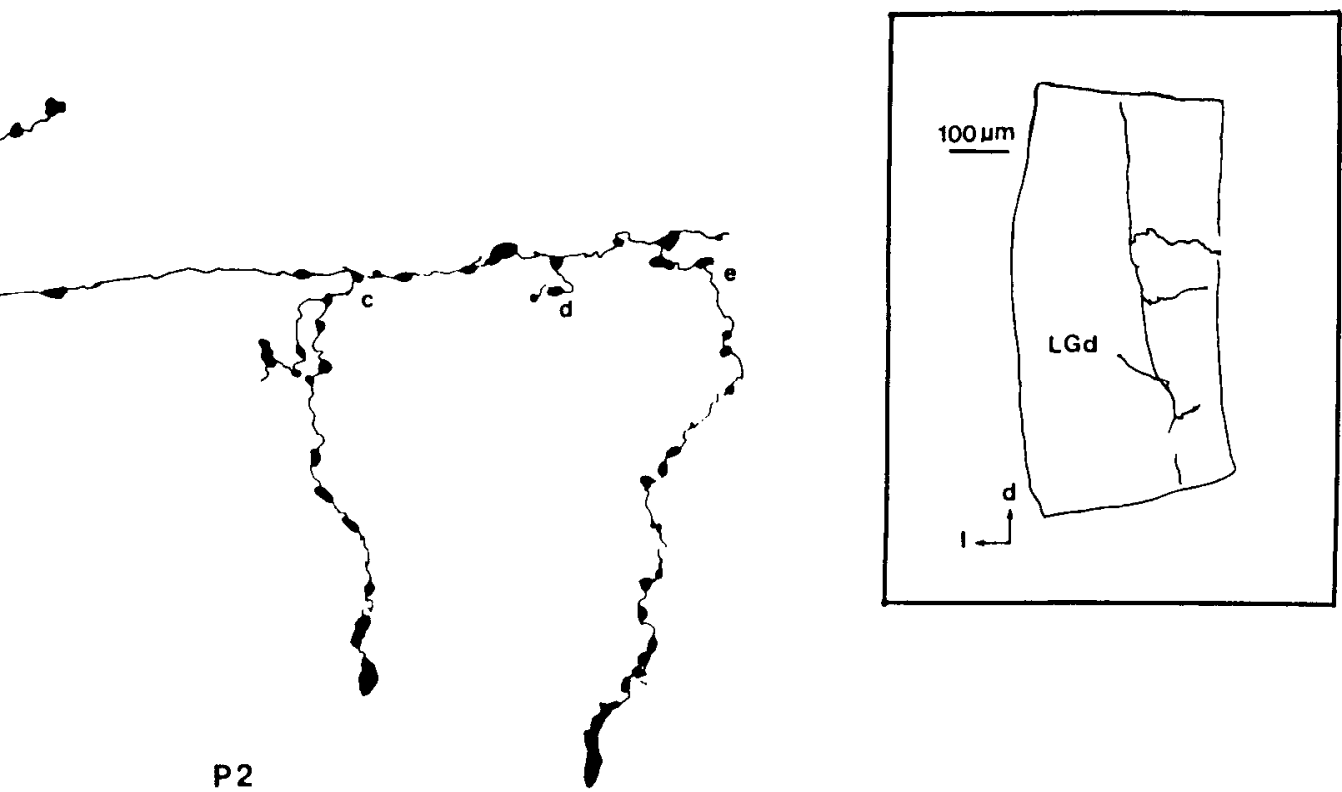

Figure 9. Camera lucida drawing of DiI-labeled, photoconverted IOT axon on $P 2$ giving rise to 5 collaterals $(a-e)$. Collateral $b$ is directed towards the pial surface, while the others are directed away from the pial surface (see inset for orientation). Until P0, virtually all the IOT collaterals are directed away from the pial surface, whereas by P4, most are directed towards the pial surface (see also Figs. 8, 10). $p$ indicates the direction of the pial surface, $l$ indicates lateral, and $d$ indicates dorsal.

and probably representing developing synaptic boutons, are common. Growth cones are absent, and a few growing tips are present, but most collaterals give rise to developing arbors.

P15. Collaterals resemble those seen on P12 (Fig. 5d,e). The 3 types of terminal arbors, R1, R2, and R3 (Figs. 6, 7d-f), and the large-, medium-, and fine-caliber axons (not illustrated) described in the LGd of the adult hamster by Erzurumlu et al. (1988) are first distinguishable at this age. Type R1 arbors consist of large ovoid boutons situated along large-caliber axons forming relatively loose tangles. Type $\mathrm{R} 2$ arbors consist of small boutons along fine-caliber axons forming relatively tightly folded clusters. Type $\mathbf{R} 3$ arbors have intermediate boutons arranged in a variety of configurations. Details of the morphology of the arbors and the differential distribution of the 3 types within the LGd were not quantitatively analyzed. Many of the arbors at this age are still maturing and cannot be classified into any of the 3 types.

P24 to adult. On P24, virtually all the arbors could be classified into one of the 3 types described in the adult by Erzurumlu et al. (1988). Between P24 and adulthood, there were no qualitative changes in the morphology of the arbors, though it appeared that the area occupied by each type of arbor decreased during this period.

Summary. Elongating SOT axons bearing complex growth cones are frequently present at the level of the LGd between E14 and PO. SOT axons emit short, unbranched or poorly branched collaterals to the LGd, bearing simple growth cones, by $\mathrm{P} 0$. These collaterals begin to arborize in the LGd by $\mathrm{P} 4$, and, by P15, the 3 types of arbors present in the adult can be distinguished. We did not observe regressing or degenerating SOT axon collaterals in the LGd at any age. It is possible that some SOT collaterals regress but were missed because they are rare compared to SOT collaterals that remain permanently.

\section{IOT axons and collaterals}

E14. Some RGC axons can already be assigned to the IOT because they leave the main OT at the ventral edge of the LGv and pass towards the midbrain parallel to the pial surface but deep in the LGv and LGd. IOT axons have prominent varicosities but do not yet have collaterals. Over the range of ages we have examined, the IOT is virtually devoid of elongating RGC axons bearing complex growth cones in the region of the LGd and LGv; only one such axon was observed (Fig. $2 f$ ).

$P 0$ and $P 2$. Fascicles of RGC axons run at least $75 \mu \mathrm{m}$ deep to the pial surface. Almost every axon emits collaterals; multiple collaterals commonly emerge from a single axon (Figs. 8c, arrows; $9,10 b$, arrows). The collaterals are approximately 50-100 $\mu \mathrm{m}$ in length (Figs. $3 a-d, 8 a-h$ ). They are always directed away from the pial surface on $\mathrm{P} 0$, but on $\mathrm{P} 2$ some are directed towards the pia (Figs. 9, 10c). From P2 onwards, collaterals directed away from and towards the pia may be seen on the same IOT axon (Fig. 9). The collaterals have simple growth cones (Figs. $8 a-h, 9)$. Some collaterals have primitive terminal arbors (Fig. $10 c$ ); others may bifurcate, and each branch may terminate in a growth cone (Fig. $8 b$ ). Some collaterals terminate in bifurcated growth cones (Fig. 3d).

same axon trunk. Until $P O$, virtually all IOT axon collaterals are directed away from the pial surface, whereas by $P 4$, most are directed towards the pial surface. On $P 9$, most IOT axons have short, unbranched collaterals without terminal specializations, as shown in $m$ and $n$. Occasionally, some may have primitive terminal arbors, as in $o$ or may be relatively long but without a terminal specialization, as in $p$. The open arrows in $i-l$ indicate the main IOT axon trunk. The breaks in the drawings of collaterals $j$ and $l$ are the result of discontinuous labeling similar to that described for Figure $4 l, p$ indicates the direction of the pial surface. 

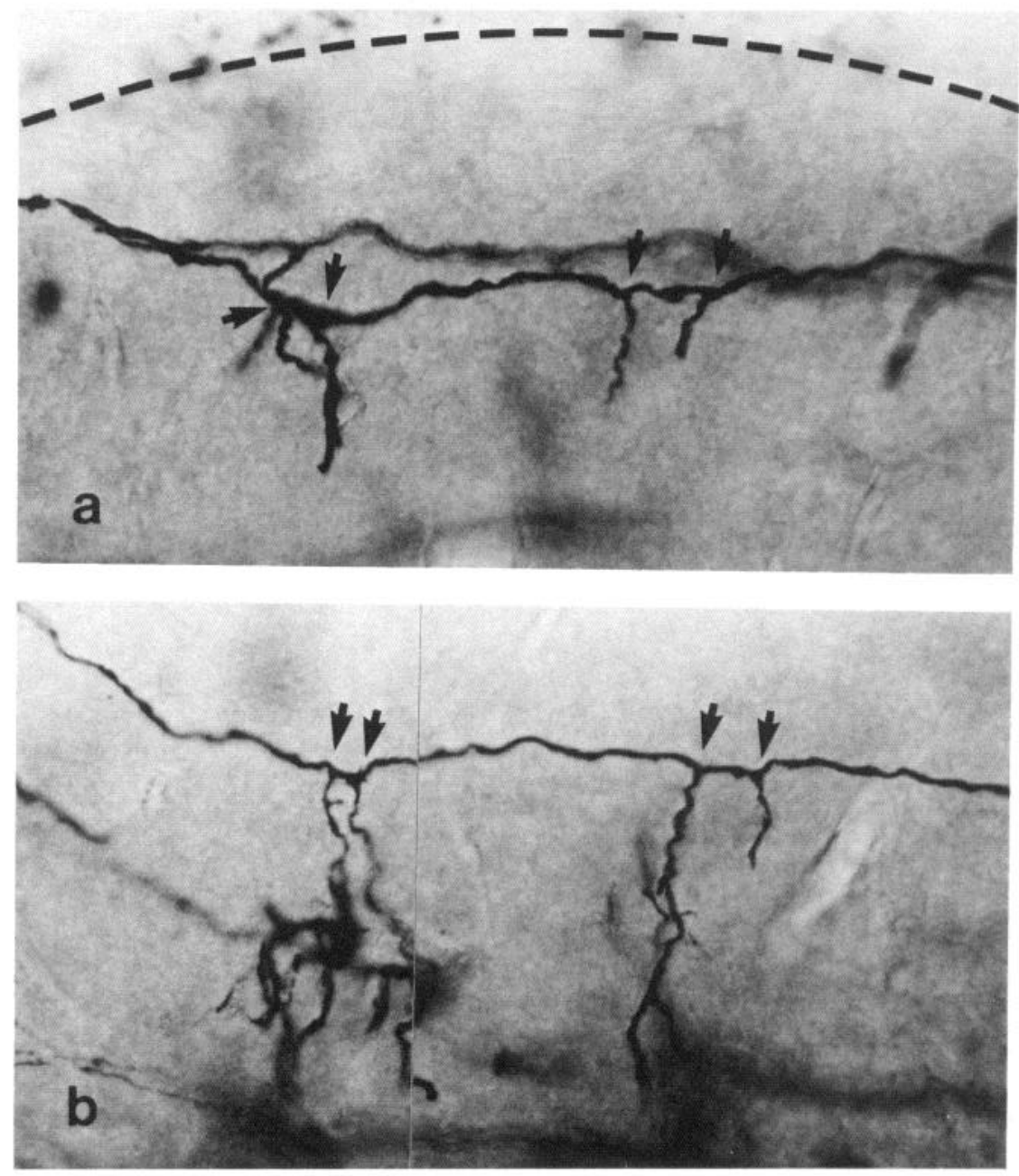

Figure 10. DiI-labeled, photoconverted SOT and IOT axons and collaterals on P2. Four collaterals (arrows) emerge from a single SOT axon in $a$ and from a single IOT axon in $b$. The IOT collaterals appear to be more mature than the SOT collaterals in that they are longer. An IOT axon in $c$ emits a collateral that is directed towards the pial surface, unlike the collaterals in $a$ and $b$, all of which are directed away from the pial surface. The collateral in $c$ has a primitive terminal arbor. The broken lines in $a$ indicate the pial surface. $b$ and $c$ are oriented the same as $a$.

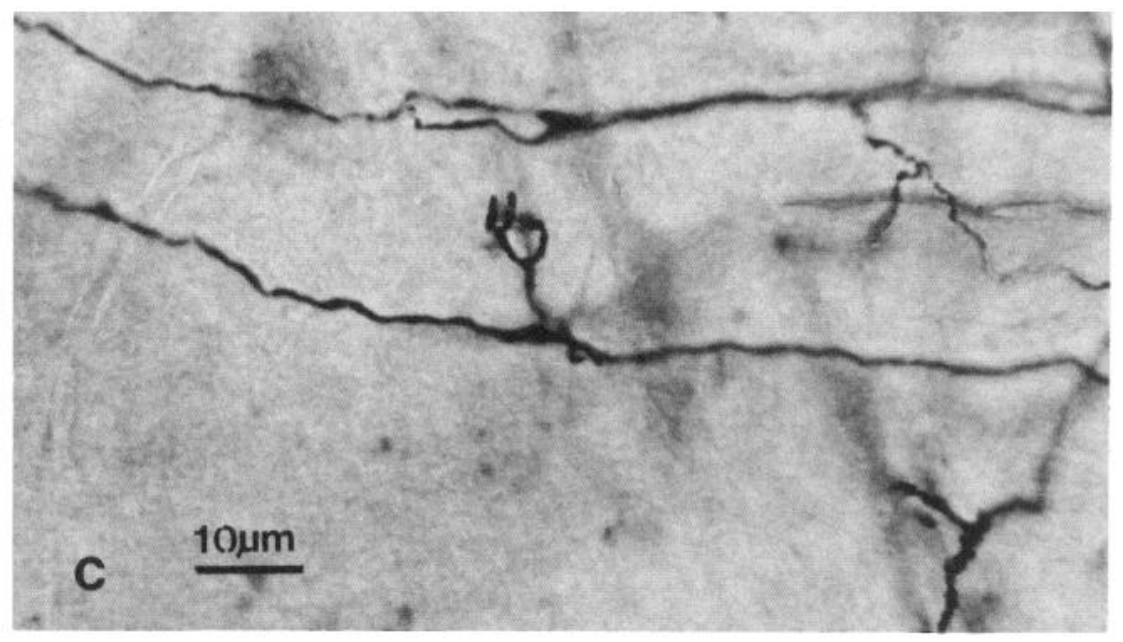

Between P0 and P3, some collaterals of IOT axons extend away from the pial surface beyond the external medullary lamina and enter the ventrobasal nucleus (VB). The development of these transient, retino-VB collaterals is described in detail by Langdon and Frost (1990) and therefore are not described here.

P4. IOT axon collaterals with a range of lengths are seen. Many are longer than those seen on P2. Although a few IOT collaterals are still directed away from the pial surface (Fig. $8 i$ ), most are oriented toward it (Fig. $8 j-l$ ). The same axon may have collaterals directed both away from and toward the pia. Some collaterals terminate in growing tips (Fig. 8i). Primitive arbors spanning an area approximately $60 \mu \mathrm{m}$ in diameter are more frequent than on P2 (Fig. $8 j-l$ ).

$P 9$. IOT axon collaterals may be as short as $5 \mu \mathrm{m}$ (Fig. $8 \mathrm{~m}$ ) or as long as $200 \mu \mathrm{m}$ (Fig. $8 p$ ). They lack terminal specializations (e.g., growth cones) or terminal arbors. The collaterals are gen- 


\section{IOT}
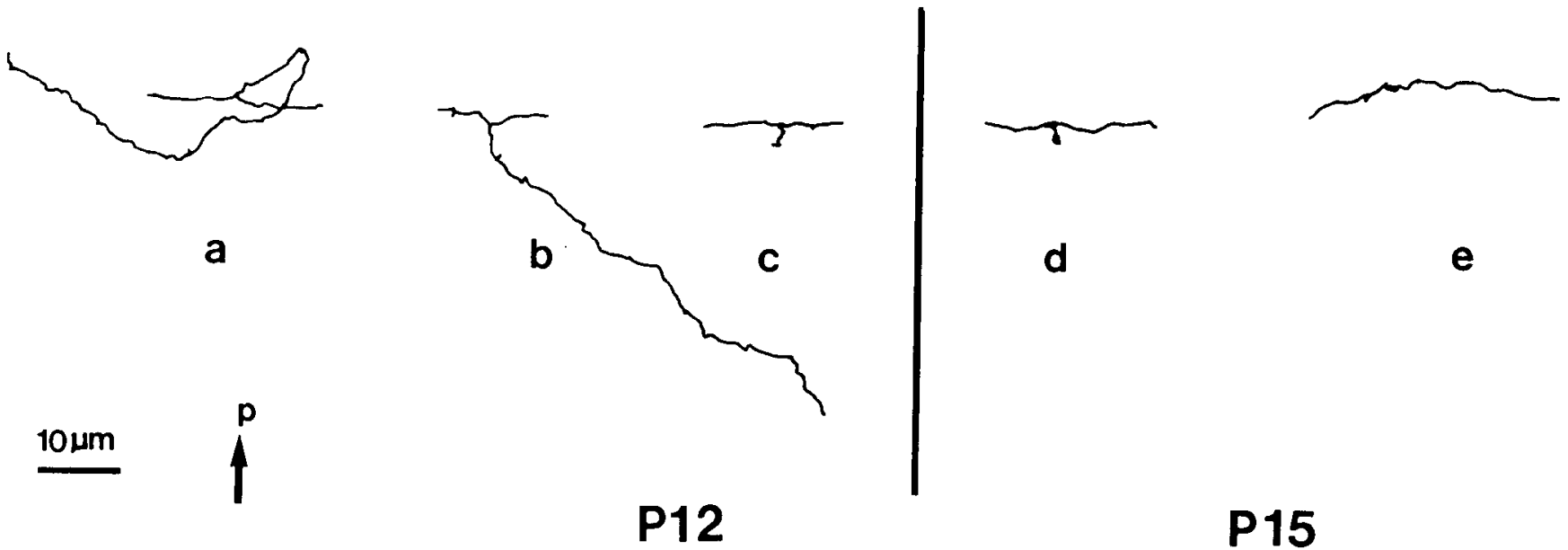

Figure 11. Camera lucida drawings of DiI-labeled, photoconverted IOT axon collaterals. On P12, the collaterals are unbranched and without terminal specializations $(a-c)$. Most are very short, as in $c$. On P15, most IOT axons are devoid of collaterals, as in $e$. Occasionally, some may have a very short, unbranched collateral as in $d . p$ indicates the direction of the pial surface.

erally shorter than those seen on $\mathrm{P} 4$, and the number of collaterals per axon is also smaller than that on P4. Collaterals may be directed either towards or away from the pial surface; single axons can bear multiple collaterals, some of each orientation. Because of the sampling problem inherent in our procedure for selecting axons for reconstruction (see "Technical comments"), a quantitative analysis of these features was not performed. The reduced number and length of IOT axon collaterals and the absence of terminal specializations suggests that, by $\mathrm{P} 9$, these collaterals are regressing.

P12. The collaterals are generally only about $5 \mu \mathrm{m}$ long (Fig. $11 c$ ) and without a terminal specialization. They may be directed either away from or toward the pial surface. Occasionally, a collateral may he 50-75 $\mu \mathrm{m}$ long (Fig. $11 a, b$ ). Many of the axons had no collaterals, and the number of collaterals per axon appeared smaller than on P9.

P15. IOT axons are generally devoid of collaterals (e.g., Fig. 11 e). Occasionally, a short, regressing collateral, about $3 \mu \mathrm{m}$ in length, may be seen (Fig. 11d ). Most IOT axons closely resemble those in the adult in that they lack collaterals.

Summary. IOT axons can be recognized by E14. Over the age range that we have examined (E14 onwards), at the level of the LGd, IOT axon trunks tipped with growth cones are not present. Collaterals from IOT axons to the LGd are well developed by $\mathrm{P} 0$ and have simple growth cones at their tips. The collaterals begin to form primitive arbors by $\mathrm{P} 2$, but the arbors regress before they are ever well developed and are completely eliminatcd by P9. The collaterals themselves begin to regress by $\mathrm{P} 9$ and are virtually completely eliminated by P15. Few, if any, mature IOT axons have thalamic collaterals.

\section{Discussion}

In mature hamsters, RGC axons may be divided into 2 distinct categories based on their trajectories and sites of termination:
SOT axons pass on the surface of the diencephalon, emit collaterals that arborize in the LGd, and terminate in the midbrain. IOT axons pass through the LGd without emitting collaterals and terminate in the midbrain. During normal development, IOT axons emit transient collaterals to the LGd. These data suggest that all RGC axons, whether in the SOT or the IOT, initially follow the same development program and project to the same set of targets. Subsequently, inappropriate projections are eliminated. This developmental strategy appears to be paradigmatic for the formation of many long axonal pathways in the CNS. This view suggests that the transient thalamic projections of IOT axons and the transient projections of other axon populations may arise as a result of the simplification of developmental rules. In this section, ontogenetic changes in the morphology, trajectories, and branching patterns of RGC axons are interpreted in terms of distinct axonal growth states.

\section{Labeling techniques}

DiI labeling in fixed tissue was superior to HRP labeling in living brain slices maintained in vitro: Growth cones and their filopodia and lamellopodia, as well as axon terminals, were more reliably labeled by DiI. Deposition of DiI in fixed tissue was easier than that of HRP in living slice preparations. Good structural preservation was more often obtained with DiI labeling in fixed tissue than with HRP labeling in in vitro slice preparations. The in vitro DiI technique also gave superior ultrastructural preservation (Bhide and Frost, unpublished observations.) Furthermore, the deposition of DiI in the retina and optic nerve ensured that only RGC axons were labeled. Deposition of HRP in the OT may label axons of nonretinal origin (Reese, 1987b); also, the HRP deposit often entered the geniculate neuropil and labeled geniculate neurons, glia, and their processes, complicating the task of identifying retinofugal axons. However, HRPlabeled retinofugal axons could be distinguished with reasonable 
certainty on the basis of their coincidence in lime and space with retinofugal axons labeled by intraocular injection of HRP (Frost, 1984) or DiI (present study).

The 2 obvious disadvantages of the use of Dil in fixed tissue are the relatively long time required for diffusion of the dye and the poor resolution of labeled axons in hamsters older than 24 $\mathrm{d}$ of age. The use of the dye in vivo overcomes both difficulties.

\section{Morphology of RGC axon growth cones}

RGC axons in the SOT growing towards their midbrain targets are tipped with complex growth cones. The complexity of growth cones decreased between E14 and P1 (cf. Figs. $1 a-d, 2$ ). Variation in growth cone morphology with age has been reported in the developing amphibian spinal cord (Nordlander, 1987), where growth cones were more complex at younger ages.

RGC axon trunks elongating towards the midbrain have complex growth cones, whereas RGC collaterals in the thalamus have simple growth cones. Differences in the morphology of growth cones on axon trunks and on collaterals have been reported in other regions of the brain. Prominent growth cones were seen on elongating axons in the cerebral peduncle and the pyramidal tract, but not on developing corticopontine collaterals (O'Leary and Terashima, 1988). Similarly, elongating axons in the corpus callosum have prominent growth cones, whereas these axons or their collaterals have simpler growth cones when they enter the cortical gray matter (Norris and Kalil, 1990). Similar observations were made in the retinotectal pathway of frogs both in vivo (Harris et al., 1987) and in fixed tissue (Fujisawa, 1987). Differences between the morphology of growth cones on elongating axon trunks and on collaterals may reflect developmental changes intrinsic to growing axons or differences between the environment provided by a fiber tract and that provided by a target region. Elongating axons in a fiber tract encounter other axons and glia, whereas axon collaterals within a target also encounter neurons that are potential synaptic partners.

What is the significance of the morphological differences between growth cones on elongating axon trunks and those on axon collaterals? As developing or regenerating axons approach a region in which they may alter their direction of growth (e.g., a peripheral nerve plexus, a CNS midline commissure, or a target region adjacent to a large CNS fiber tract), the complexity of their growth cones increases; these observations were interpreted as showing that, when growing axons enter a region where they must "make a decision" concerning their direction of growth, the complexity of their growth cones increases (Tosney and Landmesser, 1985; Bovolenta and Mason, 1987; Harris et al., 1987; Nordlander, 1987; Bernhardt, 1989). While this may be true in the PNS or in the region of a developing central commissure, our data suggest that such an interpretation of growth cone morphology may not be appropriate for RGC axons and other long CNS axons approaching prospective target regions: First, in our material, all RGC axonal processes that enter the LGd are collaterals of axon trunks that continue to the midbrain; we have never observed RGC axon trunks that leave the SOT or IOT and end in the LGd. Second, in our material RGC axon trunks tipped with complex growth cones were seen in the SOT elongating towards the midbrain, but never entering the LGd. Third, our data and those of previous studies in hamsters (Schneider et al., 1985) and frogs (Harris et al., 1987) suggest that developing RGC axons grow directly to the midbrain and do not emit collaterals to future retinorecipient regions that they encounter during their trajectory until their elongation to the midbrain is complete. These data suggest that growing RGC axons pass through a sequence of morphologically distinct growth states, 2 of which are elongation of axonal trunks and emission of collaterals (discussed below). Other long CNS axons appear to behave analogously (see below). If this view proves to be correct, then at the time that developing RGC axons tipped with complex growth cones approach the LGd, they are not in a state in which they can emit collaterals; thus, they have no decisions to make concerning their trajectories and continue to grow straight in the OT. Similarly, as other long CNS axons in the elongation state approach their targets, they need not decide whether to remain in a fiber tract or enter the targets. Growing RGC axons (and other long axons) are able to emit collaterals to their targets only when they have reached their most distant targets and the elongation state is ended. A logical consequence of this hypothesis is that changes in growth cone morphology as long axons approach their targets reflect the operation of processes other than those that will determine the axons' direction of growth. Finally, the correlation between growth cone morphology and axonal "decision making" was first proposed for developing RGC axons in the region of their targets on the basis of a small number of axons terminating in the LGv or zona incerta that had been labeled by application of HRP to the OT (Bovolenta and Mason, 1987); therefore, these axons may not even be of retinal origin.

\section{Trajectories of $R G C$ axons in the thalamus}

In hamsters, the earliest developing RGC axons emerge from the eye and traverse the optic stalk on Ell, cross the optic chiasm and course over or through the thalamus on E13, and reach the caudal end of superior colliculus (SC) on E13.5 (Jhaveri ct al., 1983a,b; Schneider ct al., 1985). Our data show that, by E14, the IOT is distinguishable in the form of axons running through the LGd. At this age, the SOT consists of elongating axons that bear complex growth cones. In our entire study, we observed only 1 elongating axon bearing a growth cone in the IOT; all other growth-cone-bearing, elongating axons were in the SOT. This suggests that new RGC axons are added primarily near the pial surface, and that axons in the IOT are, for the most part, more mature than those in the SOT. Accretion of newly arriving RGC axons just beneath the pial surface has also been observed in the case of fish (Gaze and Grant, 1978), mice (Bovolenta and Mason, 1987), rats (Reese, 1987a), cats (Torrealba et al., 1982), and ferrets (Walsh et al., 1985; Guillery and Walsh, 1987).

Axons tipped with complex growth cones are present in the IOT on E12-E13.5, ages prior to those that we have examined (S. Jhaveri and R. Erzurumlu, personal communication). However, it seems likely that, at the ages we have studied, the majority of newly arriving axons grow in the SOT and not in IOT because, even though new axons are added to both the SOT and the IOT between E14 and P1, axons bearing complex growth cones are present only in the SOT. If the developing IOT acquires its axons from the SOT, then how do some axons shift from their initially superficial position just beneath the pial surface to the depths of the LGd? One possibility, neither confirmed nor opposed by available data on the development of the hamster LGd (Crossland and Uchwat, 1982; Jhaveri et al., 1983a; Crossland, 1987), is that LGd neurons migrate past the earlier-arriving RGC axons and displace the latter to a deep location within the nucleus. A similar displacement of RGC 
axons with respect to their target neurons may also take place in the rodent SC (Edwards et al., 1986; Frost et al., 1986). However, axon trajectories may also be determined by mechanisms that are independent of the mechanisms governing neuronal migration and are disturbed by single-gene mutations (Frost et al., 1986).

\section{Axonal branching}

RGC axons reach the level of the LGd around E13, but they do not emit collaterals to the LGd until just before birth. This raises 2 points.

(1) The thalamic collaterals of retinofugal axons emerge along established axon trunks, not by bifurcation of the growing tip. This occurs after the axons have grown past the thalamus and presumably entered their targets in the midbrain (Jhaveri et al., 1983a,b; Schneider et al., 1985; present results). Collateral emission restricted to axonal trunks also occurs in other CNS projection systems, such as the neocortical projection to the basilar pons (O'Leary and Terashima, 1988), thalamocortical projections (Reinoso and O'Leary, 1988), callosal projections (Norris and Kalil, 1989), and the projection from the subiculum to the mamillary bodies (Stanfield et al., 1987); we propose that this type of axonal branching may be paradigmatic for long axonal projections involving multiple targets in the CNS. In contrast, neurites of sympathetic or parasympathetic neurons grown in culture appear always to branch by the bifurcation of the leading growth cones (Bray, 1973; Wessells and Nuttall, 1978). It is possible that the 2 types of branching (i.e., emission of collaterals from established trunks and the bifurcation of leading growth cones) occur by different mechanisms or may represent differences between the in vivo and in vitro environments.

(2) Retinofugal axons "wait" in the OT for at least $2 \mathrm{~d}$ before emitting their thalamic collaterals. Similarly, thalamic afferents to the neocortex "wait" in the intermediate zone before invading the cortical plate (Rakic, 1976; Lund and Mustari, 1977; Shatz and Luskin, 1986), and cortical afferents "wait" in the cerebral peduncle before emitting collaterals to the pons (O'Leary and Terashima, 1988). This raises the issues of whether there is an interaction between afferent axons and target neurons during the "waiting" period and, if so, what is the nature of this interaction. During the period when RGC axons "wait" in the OT overlying the LGd, dendrites of LGd neurons invaginate the RGC axon trunks and establish precocious synaptic contacts. Close to the sites of the synaptic contacts, collaterals directed towards the LGd emerge from the RGC axon trunks, suggesting an inductive role for the synaptic contacts (Bhide et al., 1988); the precise nature of the inductive signal is unknown. "Waiting" periods in other systems may also represent periods of synaptic interaction between afferents and target elements. For example, in the spinal cord, the axons of developing dorsal root ganglion cells form transient synapses on an ephemeral population of "borderline cells" before making permanent synapses in the immature dorsal horn (Knyihar et al., 1978). Similarly, thalamocortical afferents may establish transient synapses on ephemeral neurons in the subplate zone while waiting to enter the cortical plate (Rakic, 1976; Kostovic and Rakic, 1980; Chun et al., 1987; Chun and Shatz, 1988).

\section{Axonal growth states}

RGC axons appear to go through 3 morphologically defined growth states described below. Change from one growth state to the other is probably discrete in individual RGCs. However, all RGCs do no change growth states synchronously. Therefore, at some developmental stages, RGC axons in different growth states are present simultaneously (Fig. 12).

Elongation. In this state, unbranched RGC axons tipped with complex growth cones grow towards their most distant targets in the midbrain. In doing so, they pass over or through future retinorecipient regions such as the LGd, but do not emit collaterals to these regions (Fig. 13). The earliest formed $\mathrm{RGC}$ axons first enter this state when they leave the eyeball on E11 (Jhaveri ct al., 1983a,b) and remain in this statc for about 2.5 $\mathrm{d}$ until they reach the caudal limit of the SC on E13.5. Because complex growth cones on elongating axons were last seen at the level of the LGd on P1 (present results) and because elongating RGC axons grow at a rate of approximately $80 \mu \mathrm{m} / \mathrm{hr}$ (Jhaveri et al., 1983b), it appears that virtually all the RGCs have elongated to the midbrain, approximately $2 \mathrm{~mm}$ away, by the end of $\mathrm{P} 2$ or shortly thereafter.

Collateralization. In this state, RGC axons emit unbranched or poorly branched collaterals to nuclei through or over which they passed when elongating towards the midbrain (Fig. 13). In our material, collaterals of SOT axons were not present on E14 but were present on $\mathrm{PO}$; the last day at which SOT axons have collaterals bearing growth cones is P9. In another study (Jhaveri et al., 1983b), RGC axons were seen entering the LGd by EI5. Therefore, SOT axons are in the collateralization state between E15 and P9 (Fig. 12). IOT axon collaterals first emerge between E14 and P0. P4 was the last day when IOT axon collaterals with growing tips or growth cones were seen. After P4, the IOT axon collaterals appeared to be regressing rather than growing because they did not have any terminal specializations (e.g., growth cones, growing tips) or terminal arbors. Therefore, IOT axons appear to complete collateralization by P4 (Fig. 12); the IOT collaterals are virtually completely eliminated between $\mathrm{P} 12$ and $\mathrm{P} 15$ (see also Langdon et al., 1987; Langdon and Frost, 1990). On P0, IOT collaterals are directed away from the pial surface, but from P2 onwards, some may be directed toward it. The significance of the change in the orientation of collaterals is unknown. Besides terminating in the LGd, some IOT axon collaterals extend beyond the $\mathrm{LGd}$ and enter the main thalamic somatosensory (VB) nucleus. The retino-VB collaterals, like other IOT axon collaterals, are also eliminated before they elaborate terminal arbors (Langdon et al., 1987; Langdon and Frost, 1990).

RGC axons appear to emit collaterals to all their targets (except the suprachiasmatic nucleus) simultaneously, regardless of the distance of the target from the eye (Frost et al., 1979; Schneider et al., 1985). This suggests that changes in the biochemical or molecular status of RGCs characterizing the collateralization state may be simultaneously expressed along the entire length of the axon.

Arborization. In this state, RGC axons elaborate terminal arbors (Fig. 13). SOT collaterals begin arborization by P4; by P15, the 3 types of arbors present in the adult LGd are distinguishable (Fig. 6), but do not appear fully mature until P30 (data not illustrated). The formation of RGC axon synapses in the LGd temporally coincides with the elaboration of terminal arbors by SOT axon collaterals (Fig. 12; Campbell et al., 1984). IOT collaterals never form highly branched terminal arbors before being eliminated. RGC axons appear to arborize simultaneously in the LGd and SC; they begin to arborize in the LGd between P2 and P4 (present results) and in the SC by P3 (Schneider et al., 1985). It is not known whether RGC axons that project to other retinorecipient nuclei also enter the arborization state 


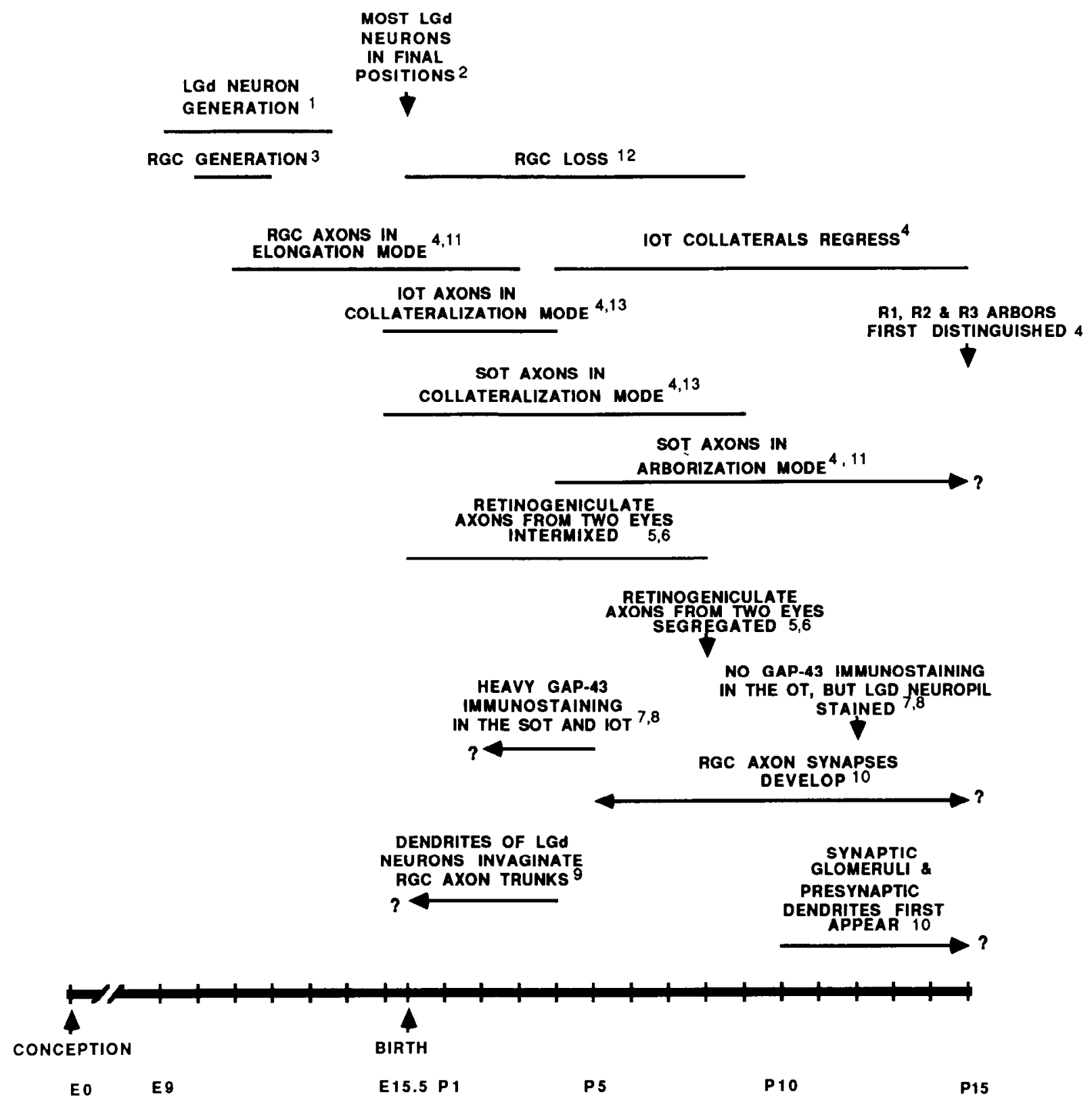

Figure 12. Summary diagram of some morphogenetic events occurring in retina, optic tract, and LGd during development of retinogeniculate pathway. Data on RGC axon elongation are from observations made in the optic nerve or SC, where it is not possible to distinguish the SOT from the IOT. Therefore, for the elongation stage, SOT and IOT are grouped together. Numbers indicate relevant references: 1 . Crossland and Uchwat, 1982; Crossland, 1987; 2. Jhaveri et al., 1983a; 3. Sengelaub et al., 1986; 4. present results; 5. So et al., 1978; 6. Frost et al., 1979; 7. Moya et al., 1988; 8. Moya et al., 1989; 9. Bhide et al., 1988; 10. Campbell et al., 1984; 11. Jhaveri et al., 1983b; 12. Sengelaub and Finlay, 1982; 13. Langdon and Frost, 1990.

simultaneously, though this would be expected if the terminal arbors in those nuclei originate from RGC axons that also terminate in the SC or LGd.

In addition to other reports of growth of hamster RGC axons in distinct, morphologically defined states (Frost, 1984; Schneider et al., 1985), mouse retinocollicular axons are also reported to develop in a similar fashion (Sachs et al., 1986). Data on the development of cortical efferent projections to the brain stem and spinal cord (Terashima and O'Leary, 1989), the fornix (Stanfield et al., 1987), auditory, somatosensory, and motor lemniscal axons (Asanuma et al., 1988), geniculocortical axons (Naegele et al., 1988), callosal axons (Norris and Kalil, 1989,
1990), and corticocortical axons (Callaway and Katz, 1990) suggest that these 3 growth states are common to other long axon pathways and to some local circuit axons.

The mechanisms by which axons shift from one growth state to the next are unknown. This question is intimately related to the question of how axons recognize appropriate targets. At least at early stages, developing RGC axons may not even recognize their appropriate targets: They initially elongate over and through the diencephalon without emitting collaterals to the LGd or LGv (Jhaveri et al., 1983a,b; Schneider et al., 1985; present results) and, in some cases, elongate beyond their most distant definitive target, the SC, to enter and make transient synaptic connections 


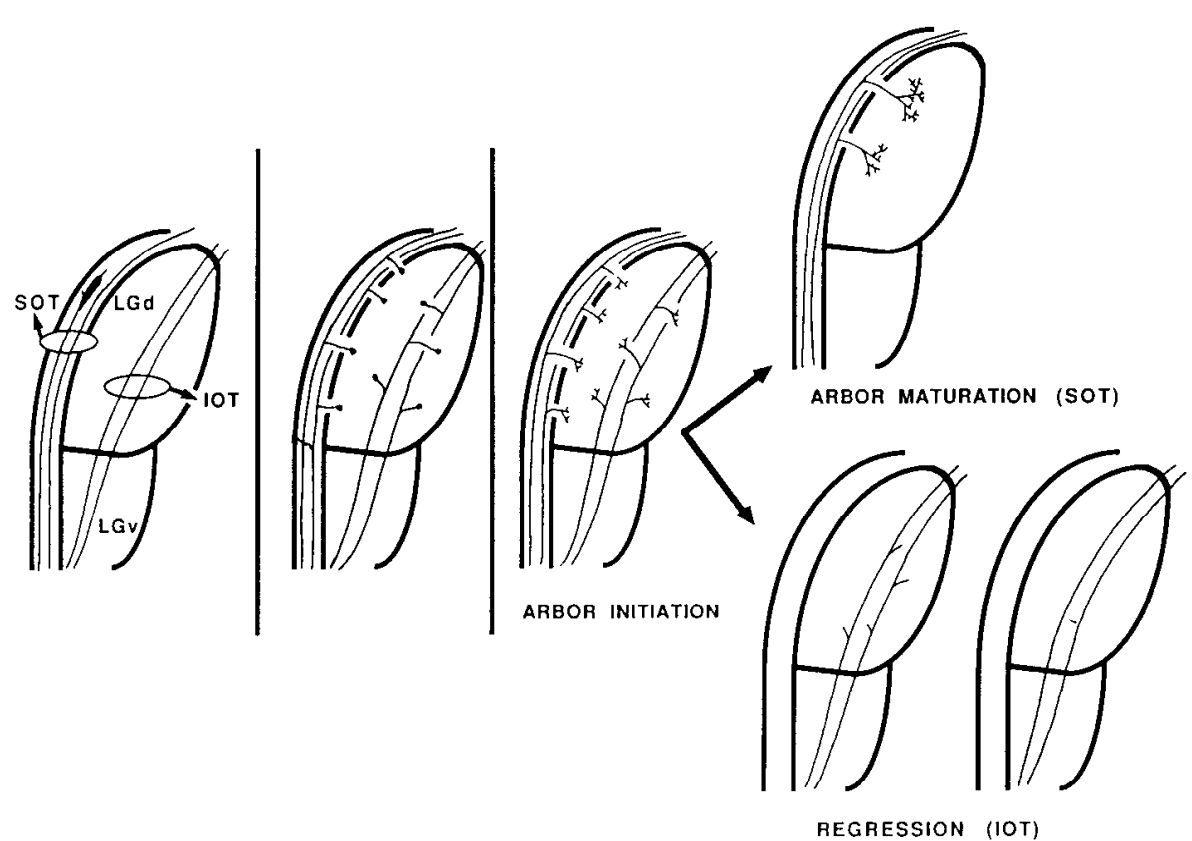

Figure 13. Schematic representation of 3 growth states in development of retinofugal axons as observed at level of LGd. The elongation and collateralization states are common to both SOT and IOT axons, but only SOT axons arborize fully in the thalamus. Even though the IOT collaterals enter the arborization state and make primitive terminal arbors, these arbors and the collaterals that bear them regress virtually completely. in an inappropriate target, the inferior colliculus (IC; Frost, 1984; Freeman and Frost, 1987). Clearly, arrival of an axon in the vicinity of a target is not sufficient to switch it from the elongation to the collateralization state. The beginning of axon collateralization may depend on an intrinsic developmental program of the neuron of origin, on extrinsic signals that the axons receive from their targets, or both. Therefore, the "waiting" period we observed may reflect either the immaturity of the RGCs or that of their targets. Several observation suggest the operation of extrinsic signals: (1) LGd neurons do not arrive at their definitive positions until E15, about the time when retinofugal axons begin to emit collaterals (Fig. 12; Jhaveri et al., 1983a). (2) When RGC axons in the SOT begin to emit collaterals, they are invaginated by the dendrites of LGd ncurons (Fig. 13; Bhide et al., 1988). At the site of invagination, precocious synaptic contacts are established, and the collaterals emerge at or near the sites of such contacts, suggesting a causal role for these interactions in the induction of collateralization. The interval between the formation of these contacts and the emission of thalamic collaterals is unknown.

\section{Elimination of transient collaterals.}

It is not possible to distinguish transient collaterals from permanent ones based on their light microscopic morphology. It is also not known if the inappropriate collaterals are eliminated by the death of their parent RGCs or by the selective regression with the retention of their main axon trunks.

Developing retino-SC (Schneider et al., 1985; Sachs et al., 1986; Simon and O'Leary, 1990) and geniculostriate (Naegele et al., 1988; Rcinoso and O'Leary, 1988) axons both transiently emit multiple, primitive collaterals, most of which are in topographically inappropriate regions of their target structures. Developing SOT and IOT axons both had multiple collaterals to the LGd (present results). In adult cats (Sur and Sherman, 1982) and hamsters (S. Jhaveri, personal communication), a single SOT axon may have multiple collaterals, all of which arborize within a restricted, topographically appropriate region of the LGd. Thus though it is possible that some of the multiple collaterals emitted to the LGd by individual, immature SOT axons are topographically inappropriate and subsequently eliminded, other collaterals may later converge and form permanent arbors in appropriate regions of the LGd. IOT axons eliminate virtually all their LGd collaterals, whether or not they are topographically appropriate, by P15.

\section{Transient projections and axonal growth state}

Different sets of transient retinal projections arise at distinct stages in the developmental history of RGC axons. The present results demonstrate that the transient thalamic projections of IOT axons arise during the stage of collateralization (Fig. 13). Transient IOT axon collaterals also give rise to temporary retinal projections to the ventrobasal nucleus (Frost, 1984; Langdon et al., 1987; Langdon and Frost, 1990). By contrast, consideration of the geometry of the OT shows that the transient retinal projection to the IC (Frost, 1984) arises during the stage of elongation: the trunks of developing RGC axons grow through the entire rostrocaudal extent of the $\mathrm{SC}$, one of their definitive targets, and extend caudally into the IC, from which they are almost entirely eliminated during the second postnatal week (Frost, 1984).

Transient connections in other systems are also associated with specific stages of axonal growth:

Elongation. In cats, retinal $\beta$ cells, which project only to the thalamus in adults, extend their trunks transiently to SC at early developmental stages (Ramoa et al., 1989). Similarly, ascending auditory, somatosensory, and cerebellar afferents to the rat thalamus initially extend rostral to their definitive termination sites and, in some instances, elongate into the internal capsule (Asanuma et al., 1988). Efferent axons of the rat occipital cortex, which do not extend caudal to the pons in adults, elongate transiently as far as the spinal cord during development (Stanfield et al., 1982); axons of the fornix, which do not extend 
caudal to the mamillary nuclei in adults, elongate to the midbrain and pontine tegmentum during development (Stanfield et al.. 1987). The definitive projections of the cortical efferent and fornix axons to more proximal targets are formed subsequent to the axons reaching their most distant targets and arise as collaterals of the overextended axon trunks, which are subsequently eliminated (Stanfield et al., 1987; O'Leary and Terashima, 1988). Finally, both retino-SC (Schneider et al., 1985; Sachs et al., 1986) and geniculostriate (Naegele et al., 1988; Reinoso and O'Leary, 1988) axons may elongate within their target structures beyond the regions in which they will terminate definitively.

Collateralization. Efferent axons from the rat motor cortex, which in adults emit collaterals to restricted regions of the pons and do not project to the midbrain, send transient collaterals to the midbrain and additional pontine areas during development; these collaterals arise subsequent to the elongation of the motor axons to their most distant definitive targets in the spinal cord (O'Leary and Terashima, 1988). Similarly, somatosensory afferents to the rat thalamus, which in adults project to the VB, emit transient collaterals to LGd at early developmental stages (Asanuma et al., 1988), and descending cortical efferents emit transient collaterals to the cerebellum (Distel and Hollaender, 1980; Adams et al., 1983; Tolbert and Panneton, 1983). Rodent retino-SC (Sachs et al., 1986), chick retinotectal (Nakamura and O'Leary, 1989), and rodent geniculostriate (Naegele et al., 1988) axons transiently emit multiple, primitive collaterals in topographically inappropriate regions of their target structures. Similarly, layer $V$ pyramidal cells in the cat visual cortex that form local circuit connections in layer III initially elaborate primitive collaterals throughout the surrounding cortical region, but later eliminate all but the collaterals to regions that contain neurons with similar ocular dominance and orientation preferences (Callaway and Katz, 1990).

Arborization. Although CNS axons may form transient connections in the elongation of collateralization stages of development, "exuberant" elaboration of terminal arbors generally appears not to occur. Our data indicate that, whereas IOT axons emit transient collaterals, these collaterals never form any significant terminal arbor before being eliminated. All of the transient axonal processes in other systems cited above are also eliminated without forming significant terminal arbors. A similar phenomenon occurs within the LGd of the cat, where the mature pattern of termination of $\mathrm{RGC}$ axon collaterals is attained by the selective elaboration of terminal arbor in the appropriate geniculate laminae and the retraction of inappropriate processes (Sretavan and Shatz, 1986). Possible exceptions to the absence of "exuberancy" in the state of arborization may underlie the transient overlapping of geniculostriatc axons representing the 2 eyes in the feline visual cortex (LeVay and Stryker, 1978) and the elaboration of terminal arbors by retinal axons in inappropriate tectal territories in the chicken (Nakamura and O'Leary, 1989).

Although transient projections appear to be generally restricted to stages of axonal development preceding the elaboration of significant terminal arbors, transient axonal processes can make synapses in their temporary targets. Transient, immature RGC axons in both the IC and the VB form synapses before being eliminated (Freeman and Frost, 1987). Similarly, transient processes of immature RGC axons form synapses in inappropriate laminae of the cat LGd (Campbell and Shatz,1986) and inappropriate sectors of the hamster LGd (Campbell et al., 1984); in the cat, these transient synapses have been shown to be functional (Shatz and Kirkwood, 1984).

\section{Significance of transient projections}

Why do RGC and other neuronal populations make transient connections, especially connections made with functionally separate systems? The significance of transient projections may be different in different instances. We propose that the transient thalamic collaterals of IOT axons may arise as an epiphenomenon of the parsimony of developmental rules. It may be more economical (e.g., in terms of genetic coding) for all RGCs to follow the same multistage developmental program, initially to elaborate the same types of connections, and then to have each distinct class of RGCs eliminate inappropriate connections, than it would be to program each class of RGCs to form only appropriate connections from the outset. This hypothesis might also apply to the transient mesencephalic projections of feline $\beta$ cells (Ramoa et al., 1989) and the initially similar (but later separate) brain-stem and spinal connections of layer $\mathrm{V}$ projection neurons in different neocortical areas of rodents (O'Leary and Terashima, 1988). While we cannot rule out the possibility that the transient thalamic projections of rodent RGC axons, especially those to the VB, are "errors" due to "slop" in the execution of their developmental program, this seems to us unlikely because of the wide variety of axon populations exhibiting similar behavior and because the developmental "errors" are made so precisely. While some transient neural connections (e.g., callosal; Frost, 1989) may provide a substrate for ontogenetic or phylogenetic modification of the CNS in response to changes in peripheral receptors or in the environment, it is difficult to imagine a possible functional significance for the transient thalamic collaterals of the IOT.

\section{References}

Adams CE, Mihailoff GA, Woodward DJ (1983) A transient component of the developing corticospinal tract arises in visual cortex. Neurosci Lett 36:243-248.

Adams JC (1981) Heavy metal intensification of DAB-based HRP reaction product. J Histochem Cytochem 29:775

Asanuma C, Ohkawa R, Stanfield BB, Cowan WM (1988) Observations on the development of certain ascending inputs to the thalamus in rats. I. Postnatal development. Dev Brain Res 41:159-170.

Bernhardt $R$ (1989) Axonal pathfinding during the regeneration of the goldfish optic pathway. J Comp Neurol 284:119-134.

Bhide PG, Lieberman AR, Campbell G (1988) Dendritic invagination of developing optic tract axons in the hamster. Exp Brain Res 73: 519-522.

Bovolenta P, Mason CA (1987) Growth cone morphology varies with position in the developing mouse visual pathway from retina to first targets. J Neurosci 7:1447-1460.

Bray D (1973) Branching patterns of individual sympathetic neurons in culture. J Cell Biol 56:702-712.

Callaway EM, Katz LC (1990) Emergence and refinement of clustered horizontal connections in cat striate cortex. J Neurosci 10:1134-1153.

Campbell G, Shatz CJ (1986) Synapses formed by individual retinogeniculate axons in inappropriate LGN territory during prenatal development of the cat's retinogeniculate projection. Soc Neurosci Abstr 12:589.

Cambell G, So K-F, Lieberman AR (1984) Normal post-natal development of retinogeniculate axons and terminals and identification of inappropriately-located transient synapses. Neuroscience 13:743759.

Chalupa L, Thompson I (1980) Retinal ganglion cell projections to the superior colliculus of the hamster demonstrated by the horseradish peroxidase technique. Neurosci Lett 19:13-19.

Chun JJM, Shatz CJ (1988) Distribution of synaptic vesicle antigens is correlated with the disappearance of a transient synaptic zone in the developing cerebral cortex. Neuron 1:297-310. 
Chun JJM, Nakamura MJ, Shatz CJ (1987) Transient cells of the developing mammalian telencephalon are peptide immunoreactive neurons. Nature 325:617-620.

Crossland WJ (1987) Neurogenetic gradients in the hamster visual pathway. Dev Brain Res 36:314-318.

Crossland WJ, Uchwat CJ (1982) Neurogenesis in the central visual pathways of the golden hamster. Dev Brain Res 5:99-103.

Distel H, Hollaender H (1980) Autoradiographic tracing of developing subcortical projections of the region in fetal rabbits. J Comp Neurol 192:505-518

Edwards MA, Schneider GE, Caviness VS Jr (1986) Development of the crossed retinocollicular projection in the mouse. J Comp Neurol 248:410-421.

Erzurumlu RS, Jhaveri S, Schneider GE (1988) Distribution of morphologically different retinal axon terminals in the hamster dorsal lateral geniculate nucleus. Brain Res 461:175-181.

Freeman JM, Frost DO (1987) Synapse formation by optic tract axons that project transiently to somatosensory and auditory nuclei in the neonatal hamster. Soc Neurosci Abst 13:1023.

Frost DO (1984) Axonal growth and target selection during development: retinal projection to the ventrobasal complex and other "nonvisual" structures in neonatal Syrian hamsters. J Comp Neurol 230:576-592.

Frost DO (1988) Mechanisms of structural and functional development in the thalamus: retinal projections to the auditory and somatosensory systems in normal and experimentally manipulated hamsters. In: Cellular thalamic mechanisms. (Bentivoglio M, Spreafico R, eds), pp 447-464. Amsterdam: Elsevier.

Frost DO (1989) Transitory neuronal conncctions in normal development and disease. In: Brain and reading (Von Euler C, Lundberg I, Lennerstrand G, eds), pp 17-26. London: Macmillan.

Frost DO, So K-F, Schneider GE (1979) Postnatal development of retinal projections in Syrian hamsters: a study using autoradiographic and anterograde degeneration techniques. Neuroscience 4:1649-1677.

Frost DO, Edwards MA, Sachs GM, Caviness VS Jr (1986) Retinotectal projection in reeler mutant mice: relationship among axon trajectories, arborization patterns, and cytoarchitecture. Dev Brain Res 28:109-120.

Fujisawa $\mathrm{H}$ (1987) Mode of growth of retinal axons within the tectum of Xenopus tadpoles, and implications in the ordered neuronal connection between the retina and the tectum. J Comp Neurol 260:127139.

Gaze RM, Grant PK (1978) The diencephalic course of regencrating retinotectal fibers in Xenopus tadpoles. J Embryol Exp Morphol 44: 201-216.

Godement P, Vanselow J, Thanos S, Bonhoeffer F (1987) A study of developing visual systems with a new method for staining neurons and their processes in fixed tissue. Development 101:697-713.

Guillery RW, Walsh C (1987) Changing glial organization relates to changing fiber order in the developing optic nerve of ferrets. J Comp Neurol 265:203-217.

Harris WA, Holt CE, Bonhoeffer F (1987) Retinal axons with and without their somata, growing to and arborizing in the tectum of Xenopus embryos: a time-lapse video study of single fibers in vivo. Development 101:123-133.

Innocenti GM (1986) General organization of callosal connections in the cerebral cortex. In: Cerebral cortex (Jones EG, Peters A, eds), Vol 5, pp 291-353. New York: Plenum.

Innocenti GM, Clarke S (1984) The organization of immature callosal connections. J Comp Neurol 230:287-309.

Jhaveri S, Edwards MA, Schneider GE (1983a) Relationship of lateral geniculate neuron migration to stages of optic tract growth in the hamster. Soc Neurosci Abstr 9:702.

Jhaveri S, Edwards MA, Schneider GE (1983b) Two stages of growth during development of hamster's optic tract. Anat Rec 205:225.

Keller G, Innocenti GM (1981) Callosal connections of suprasylvian visual areas in the cat. Neuroscience 6:703-712.

Knyihar E, Csillik B, Rakic P (1978) Transient synapses in the embryonic primate spinal cord. Science 202:1206-1209.

Kostovic I, Rakic P (1980) Cytology and time of origin of interstitial neurons in the white matter in infant and adult human and monkey telencephalon. J Neurocytol 9:219-242.

Langdon RB, Frost DO (1990) Transient retinal axon collaterals to visual and somatosensory thalamus in neonatal hamsters. J Comp Neurol, in press.
Langdon RB, Freeman JM, Frost DO (1987) Trajectories and branching patterns of optic tract axons that project transiently to somatosensory thalamus in the neonatal hamster. Soc Neurosci Abst 13: 1023.

LeVay S, Stryker MP (1978) Ocular dominance columns and their development in layer IV of the cat's visual cortex: a quantitative study. J Comp Neurol 179:223-244.

Linden R, Perry VH (1983) Massive retinotectal projection in rats. Brain Res 272:145-149.

Lund RD, Mustari MJ (1977) Development of the geniculocortical pathways in rats. J Comp Neurol 173:289-306.

Martin PR (1986) The projection of different retinal ganglion cell classes to the dorsal lateral geniculate nucleus in the hooded rat. Exp Brain Res 62:77-88.

Mason CA (1985) Growing tips of embryonic cerebellar axons in vivo. J Neurosci Res 13:55-73.

McConnell SK (1989) The determination of neuronal fate in the cerebral cortex. Trends Neurosci 12:342-349.

Métin C, Frost DO (1989) Visual responses of neurons in somatosensory cortex of hamsters with experimentally induced retinal projections to somatosensory thalamus. Proc Natl Acad Sci USA 86:357361 .

Moya KL, Benowitz LI, Jhaveri S, Schneider GE (1988) Changes in rapidly transported proteins in developing hamster retinofugal axons. J Neurosci 8:4445-4454.

Moya KL, Jhaveri S, Schneider GE, Benowitz LI (1989) Immunohistochemical localization of GAP-43 in the developing hamster retinofugal pathway. J Comp Neurol 288:51-58.

Naegelc JR, Jhaveri S, Schncider GE (1988) Sharpening of topographical projections and maturation of geniculocortical axon arbors in the hamster. J Comp Neurol 277:593-607.

Nakamura H, O'Leary DDM (1989) Inaccuracies in initial growth and arborization of chick retinotectal axons followed by course corrections and axon remodeling to develop topographic order. J Neurosci 9: 3776-3795.

Nordlander R (1987) Axonal growth cones in the developing amphibian spinal cord. J Comp Neurol 263:485-496.

Norris CR, Kalil K (1989) Development of callosal arbors in the hamster SM cortex. Soc Neurosci Abstr 15:874.

Norris CR, Kalil K (1990) Morphology and cellular interactions of growth cones in the developing corpus callosum. J Comp Neurol 293: 268-281.

O'Leary DDM, Terashima T (1988) Cortical axons branch to multiple subcortical targets by interstitial axon budding: implications for target recognition and "waiting periods." Neuron 1:901-910.

Rakic P (1976) Prenatal genesis of connections subserving ocular dominance in the rhesus monkey. Nature 261:467-471.

Ramoa AS, Campbell G, Shatz CJ (1989) Retinal ganglion $\beta$ cells project transiently to the superior colliculus during development. Proc Natl Acad Sci USA 86:2061-2065.

Reese BE (1987a) The distribution of axons according to diameter in the optic nerve and optic tract of the rat. Neuroscience 22:1015-1024.

Reese BE (1987b) The position of the crossed and uncrossed optic axons, and non-optic axons, in the optic tract of the rat. Neuroscience 22:1025-1039.

Reinoso BS, O'Leary DDM (1988) Development of visual thalamocortical projections in the fetal rat. Soc Neurosci Abstr 14:1113.

Sachs GM, Jacobson M, Caviness VS Jr (1986) Postnatal changes in the pattern of arborization of murine retinocollicular axons. J Comp Neurol 246:395-408.

Sandell JH, Masland RH (1988) Photoconversion of some fluorescent markers to a diaminobenzidine product. J Histochem Cytochem 36: $555-559$.

Schneider GE, Jhaveri S (1983) Projections of the internal optic tract: retinal projections that survive superficial thalamic lesions in the hamsters. Soc Neurosci Abst 9:809.

Schneider GE, Jhaveri S, Edwards MA, So K-F (1985) Regeneration, rerouting and redistribution of axons after early lesions: changes with age and functional impact. In: Recent advances in restorative neurology, upper motor neuron function and dysfunction (Dimitrijevic M, Eccles JC, eds), pp 291-310. Basel: Karger.

Sengelaub DR, Finlay BL (1982) Cell death in the mammalian visual system during normal development: I. Retinal ganglion cells. J Comp Neurol 204:311-317.

Sengelaub DR, Dolan RP, Finlay BL (1986) Cell generation, death, 
and retinal growth in the development of the hamster retinal ganglion cell layer. J Comp Neurol 246:527-543.

Shatz CJ, Kirkwood PA (1984) Prenatal development of functional connections in the cat's retinogeniculatc pathway. J Neurosci 4:13781397.

Shatz CJ, Luskin MB (1986) The relationship between the geniculocortical afferents and their cortical target cells during development of the cat's primary visual cortex. J Neurosci 6:3655-3668.

Simon DK, O'Leary DDM (1990) Limited topographic specificity in the targeting and branching of mammalian retinal axons. Dev Biol 137:125-134.

So K-F, Schneider GE, Frost DO (1978) Postnatal development of retinal projections to the lateral geniculate body in Syrian hamsters. Brain Res 142:343-352.

Sretavan DW, Shatz CJ (1986) Prenatal developmental of retinal ganglion cell axons: segregation into eye-specific layers within the cat's lateral geniculate nucleus. J Neurosci 6:234-251.

Stanfield BB, O'Leary DDM, Fricks C (1982) Selective collateral elimination in early postnatal development restricts cortical distribution of rat pyramidal tract neurones. Nature 298:371-373.

Stanfield BB, Nahin BR, O'Leary DDM (1987) A transient postmamillary component of the rat fornix during development: implication for interspecific differences in mature axonal projections. J Neurosci $7: 3350-3361$.
Sur M, Sherman SM (1982) Retinogeniculate terminations in cats: morphological differences between $X$ and $Y$ cell axons. Science 218: 389-391.

Terashima T, O'Leary DDM (1989) Growth and branching of cortical axons: implications for target selection by developing axons. Soc Neurosci Abst 15:875.

Tolbert DL, Panneton WM (1983) Transient cerebro-cerebellar projections in kittens: postnatal development and topography. J Comp Neurol 221:216-228.

Torrealba F, Guillery RW, Eysel U, Polley E, Mason CA (1982) Studies of retinal representations within the cat's optic tract. J Comp Neurol 211:377-396.

Tosney KW, Landmesser LT (1985) Growth cone morphology and trajectory in the lumbosacral region of the chick embryo. J Neurosci 5:2345-2358.

Walsh C, Price S, Guillery RW (1985) Age-related fiber order in the optic tract of the ferret. J Neurosci 5:3061-3069.

Wessells NK, Nuttall RP (1978) Normal branching, induced branching and steering of cultured parasympathetic motor neurons. Exp Cell Res 115:111-112.

Wise SP, Jones EG (1977) Cells of origin and terminal distribution of descending projections of the rat somatic sensory cortex. J Comp Neurol 175:129-158. 